\title{
ACTUALIDAD Y EJEMPLARIDAD DEL DERECHO ROMANO
}

Jesús DAZA MARTINEZ

Catedrático de Derecho Romano 



\section{1.- LA CIENCIA DEL DERECHO ROMANO Y LA CIENCIA DEL DERECHO EN GENERAL}

El presente trabajo ha sido pensado y estructurado a partir de la convicción básica de que la Ciencia del Derecho romano constituye el fundamento y la raíz misma de la ciencia del Derecho en general(1). En este sentido, la Jurisprudencia romana se revela como la expresión más alta de la auténtica conciencia juridica y es, por tanto, un punto permanente de referencia para cualquier intento de comprensión del Derecho en cuanto fenómeno humano social, cultural e histórico. De ahí la universalidad de su método, de su contenido y de su espíritu(2).

En primer lugar, es cierto que-como observa D‘ORS-la función primordial del Derecho romano no estriba tanto en su capacidad de aproximarnos a la genealogía de los Códigos civiles como en servir para el descubrimiento de lo que le pasa al Derecho moderno(3). En otras palabras, no es aceptable el intento de conciliación entre la ciencia del Derecho y el respeto que se debe a la Jurisprudencia romana afirmando de forma general que los juristas romanos fueron "unos empíricos geniales". Comentando esta expresión de DE FRANCISCI, ha observado BIONDI con agudeza que "la frase nasconde garbatamente la condanna sotto lo aspetto scienfificow(4). El mismo autor explica las razones que han conducido en algunos casos a un distanciamiento entre la Jurisprudencia romana y la contemporánea, viendo en este hecho una de las causas del desinterés hacia el Derecho romano mismo(5). Aunque se continúa repitiendo que los juristas romanos han creado la ciencia del Derecho, en realidad se acepta de hecho que se trata de un sistema imperfecto, tanto en sus principios como en sus definiciones.

El problema, pues, va más allá y obliga a replantear el concepto moderno de ciencia jurídica y el sentido último que subyace al esfuerzo de sistematización y de reducción a la unidad que le es propio, más quizá de lo que ocurre en otras ciencias sociales.

En efecto, tradicionalmente los juristas tienden a mantener que su tarea consiste sobre todo en poner un orden en el material normativo que tienen delante, reduciendo a unidad los múltiples elementos que se con- 
tienen en él, a diferencia de lo que sucede en las ciencias naturales en las que ocupa el primer plano el intento cognoscitivo en sentido estricto, esto es, la obtención de nuevos conocimientos(6). Se trata, pues, de un trabajo de ordenación cuyo fin último es la construcción de un sistema, entendido como un conjunto de clasificaciones en las que se definen y delimitan las relaciones entre cada una de las clases de elementos.

La actividad de la ciencia jurídica se ha polarizado excesivamente en esta dirección, como consecuencia de la filosofía iuspositivista imperante; sobre todo, el positivismo jurídico que se inspira en la obra de KELSEN considera como uno de los elementos principales para distinguir la ciencia jurídica de las ciencias empíricas esta voluntad de sistematización y ve en ella una forma de rechazo de los ataques que provienen del empirismo sociologico.

Sin embargo, no parece totalmente aceptable la elección de este criterio para caracterizar la ciencia jurídica, porque deja fuera otros elementos igualmente importantes de ella. E. DI ROBILANT ha insistido en señalar que la respuesta implícita en la concepción que tiene el positivismo jurídico de KELSEN de la ciencia jurídica como ciencia de normas, es incompleta y puede ser, por tanto, desorientadora. En primer lugar es una respuesta en la cual está latente el prejuicio que domina a todo el positivismo jurídico y que desconoce que la realidad es más compleja y no admite una simplificación que la reduce o mutila. La representación del Derecho que se encuentra en él tiene el carácter de un modelo, o de un conjunto de modelos e intenta descubrir, de forma esquemática y abreviada "alcuni nessi individuabili nella realtà giuridica»(7). Así pues, sólo aparece aceptable como un modelo de un caso límite que no se presenta en la realidad en su estado puro. Este tipo de representación puede tener una gran utilidad científica, pero no puede en modo alguno identificarse con la realidad misma, y menos aún ser considerado como exclusivo y omnicomprensivo. Porque los juristas, al hacer sus sistematizaciones no parten sólo de normas abstractas sino de fenómenos de la realidad social, de la cual las normas no son sino manifestaciones. En otras palabras, el Derecho no es un conjunto de ideas abstractas y desvinculadas de la experiencia, sino un conjunto de fenómenos de la realidad, aunque después el jurista, para 
simplificar su estudio, construye uno o varios modelos a través de un proceso de abstracción o de invención.

Aquí es justamente donde el Derecho romano se revela particularmente eficaz y fecundo, por aquella "viva aderenza al concretow(8) que le es propia. Porque el Derecho-cuya sistematización pretende ofrecer el juristapertenece siempre a uno o más ordenamientos y constituye, por tanto, un fenómeno social completo, que como tal debe ser interpretado. Así pues, cualquier intento de aproximación y sistematización de las normas jurídicas exige tener presente su función en la realidad social a la que pertenecen y en la cual operan, aunque esto no significa que la ciencia jurídica se reduzca a sociología o ideología(9).

En suma, no es posible ignorar la conexión entre teoría (en el sentido de sistematización) y realidad empírica. Por otra parte, esta relación se establece necesariamente mediante un determinado cuadro categorial, esto es, recurriendo al uso de un conjunto de definiciones, conceptos y esquemas. En este sentido, las teorias, en cuanto sistematizaciones, no se encuentran en una situación cualitativamente distinta de la que es propia de las teorías como representaciones de la realidad y de aquellas otras teorias que son propias de las ciencias empíricas en general(10).

En cualquier caso, es indudable que nuestros procedimientos de abstracción y nuestras exigencias de categorias generales pueder servir para un mejor conocimiento y profundización científica del Derecho romano. Pero, por otra parte, debe afirmarse también que en los conflictos de tendencias que presenta hoy la elaboración del derecho es de gran utilidad la consideración del método y la técnica de los juristas romanos, que siempre se mantuvieron próximos a la vida empírica del Derecho, tal como surgia y se desarrollaba en su realidad inmediata. No basta la afirmación genérica de que su lógica era inductiva y empírica; porque-como subraya GROSSO(11) - todo este empirismo está guiado por un claro sentido de la construcción: ésta se expresa en figuras bien delineadas, desarrollándose a través de diversos tipos, apoyándose siempre en lo concreto, distinguiendo las figuras y conceptos e individuando claramente la realidad jurídica. Lo que la caracteriza es su escasa propensión hacia las teorias generales y hacia los conceptos abstractos, es decir, el operar con figuras 
que conservan "una tangible concretezza»(12) y su elaboración y desarrollo en estrecha vinculación con la aplicación práctica.

Esto supuesto-y tal como ya entrevio SAVIGNY - cuando se habla del valor permanente del Derecho romano hay que hacer referencia sobre todo al método de los juristas y no al contenido de las normas que componian aquel derecho(13). Aunque es cierto que, a diferencia de otros derechos del mundo antiguo, el Derecho romano se afirma con la estructura de un verdadero "sistema", su superioridad deriva, a su vez, de la técnica de sus constructores, esto es, del método de los iuris-prudentes. Su lógica se mueve de los hechos a las generalizaciones; cuando llega a una determinada regla no permanece esclava de ella ni presupone que ha llegado al fin de la búsqueda: no la considera como un dogma, sino como una formula válida en relación con los hechos sobre los cuales ha sido construida, como un instrumento de trabajo. Para los juristas romanos el criterio de la verdad de una fórmula o de la bondad de un instituto viene dado por su aplicabilidad y utilidad; ponen sus procedimientos técnicos al servicio de la acción y de la vida, que es siempre más rica, compleja y varia que cuanto puede caber en los silogismos. Por este motivo, sin duda, se han resistido a formular teorías generales. Pero aplicando a todos los campos su sentido de la realidad-y, por tanto, de la estructura y de las finalidades prácticas de cada instituto-, saben promover el desarrollo sin alterar, como dice DE FRANCISCI, "la compagine organica ed originaria»(14).

Gracias a la constante aplicación de estos métodos, siempre adaptados a las nuevas necesidades y a los intereses reales de cada momento, la construcción alcanza unas proporciones y un equilibrio tales que, a pesar de las influencias que recibió como consecuencia de la extensión del Derecho romano a las provincias, pudo mantener su línea inalterada, acogiendo incluso nuevos principios y nuevos institutos.

En su importante monografía relativa a esta temática, KASER subraya, ante todo, que la manera que tenían los romanos de ver casuísticamente su derecho, esto es, desde la perspectiva del caso concreto, domina todos los períodos de la historia de su Derecho'15). Aunque haya habido actos de codificación (la Ley de las XII Tablas en los tiempos primitivos y el Corpus luris al final de la Edad Antigua), éstos no exclu- 
yen que el carácter total del Derecho romano, y concretamente el clásico, venga determinado por el hecho de que el conjunto de las ideas jurídicas se encarna en los problemas casuísticos que los juristas exponen y resuelven.

Para los romanos, dice BIONDK(16), la jurisprudencia no es ciencia en el sentido de investigación de una verdad objetiva, ni especulación abstracta en torno al ordenamiento jurídico, sino más bien actividad intelectual encaminada a conseguir lo que es justo y oportuno en la vida social, en la convivencia. La prudentia no es la sapientia o conocimiento en sí, sino más bien, según la fórmula de CICERON, la «rerum expetendarum fugiendarumque scientiaw(17). En contacto con la vida, buscan satisfacer las necesidades sociales en el ámbito del derecho. No imponen a sus conciudadanos el producto de las especulaciones, sino que sugieren fórmulas y proponen soluciones que responden a la justicia. Esta es la razón por la cual el ius civile se ha formado en gran parte fuera del Estado, por obra de los iuris conditores.

Aparte de la casuística, el método de los juristas romanos estaba basado en la intuición y en la elaboración jurídica racional. En la época arcaica dominó, sin duda, la creación jurídica intuitiva, pero con el tiempo aparece también la tendencia a motivar con razones de tipo material las soluciones encontradas, si bien la intuición jurídica continúa siendo el factor clave que controla el proceso racional. Examinando los moldes categoriales en que cristaliza el método racional de los juristas romanos, KASER destaca cómo en unos casos no acuden a otras normas o conceptos jurídicos sino directamente a la justicia material, esto es, a la realización concreta de la ética jurídica específica. En otras ocasiones, rompen el marco del tema con su argumentación individual, refiriéndose a casos parecidos o contrarios, o apoyándose en una norma jurídica abstracta o en una delimitación conceptual independiente. Estas normas creadas por los juristas no se presentan como vinculantes, sino que se trata más bien de un mero juicio de la experiencia sobre el pasado. Existen también otras normas formuladas de modo general y llamadas regulae, que conducen a. la formación de juicios de contenido jurídico, aunque no son tampoco fuente de conocimiento del derecho, sino que reflejan únicamente a éste, tal y como se manifiesta en las resoluciones casuísticas concretas(18). 
El método de los juristas romanos se basaba también en las definiciones. En un estudio importante dedicado a esta temática, A. CARCATERRA(19) hace notar que mientras el derecho positivo se sirve, como la ciencia y la enseñanza, de los términos de la lengua común y de los términos técnicos (nomina iuris), no acostumbra a definirlos; en cambio, la didáctica y la ciencia proceden metódicamente a dar el significado de estos términos técnicos e incluso, algunas veces, de los términos de la lengua ordinaria. Además de la enseñanza y de la investigación científica, los juristas romanos tienen en cuenta al servirse de la definitio otros fines: la vulgarización y la legislación (casi nunca durante el período clásico).

La definitio, según señala el mismo CARCATERRA(20), ha sido verdaderamente útil para la sciencia iuris, de los juristas romanos, para su fundamentación y progreso (ya se trate de definiciones etimológicas, ejemplificadoras, descriptivas o-más ordinariamente-per divisionem o partitionem). En particular, los comentarios al Edicto o a Edictos especiales no son, como sostiene SCHULZ(21), una masa "di fatispecie eterogenee messe insieme alla carlona", sino que estos comentarios tienen como fundamento precisamente la definitio. Así Labeón, a quien seguirá más tarde Ụlpiano, casi todas las veces que se ha ocupado de rúbricas y de enunciados edictales, ha definido los términos fundamentales (edere, parentes, metus, bonorum possessio, cognati...(22). La definitio muestra su mayor utilidad en cuanto se refiere a la caracterización y al análisis de los elementos constitutivos de un concepto o de un istituto. Los Topica de Cicerón, escritos para juristas, se abren con la definición y la indicación de los fines de los topoi, entre los cuales figura la definitio; ésta, a su vez, se sirve de los topoi, como la partitio, o lovioci ex coniugatis, ex genere, ex similitudine.

En suma, la definitio obliga a buscar las causas, los orígenes, las distinciones, las partes de un instituto jurídico, asi como a sintetizar los resultados. No es extraño que pueda y deba considerarse como una contribución importante a la creación de la scientia iuris. El mismo CICERON dejó escrito que "omnis institutio debet a definitione proficiscin(23).

La metodología de los juristas romanos se basó también, en algunos casos, en la retórica, si bien las notas comunes de ésta con la Jurisprudencia, como señala KASER, “tocan pronto a su fin»(24). La retórica no tendió 
en cada caso concreto a la realización de la justicia, ni tuvo nada que ver con el conocimiento intuitivo del Derecho, persiguiendo más bien éxitos puramente externos y éticamente dudosos. Se servía de modelos griegos y utilizaba una dialéctica refinada, pero permaneció siempre por debajo de la jurisprudencia.

Esta visión panorámica no puede perder de vista tampoco el hecho de que la exposición racional de los institutos del ius privatum según su esquema expositivo orgánico, fue, en expresión de GUARINO, la última entre las preocupaciones de la Jurisprudencia romana(25). Como ya señalamos anteriormente, la orientación de los juristas era hacia las consideraciones prácticas más que hacia la síntesis. Ciertamente, en la última jurisprudencia preclásica y posteriormente en la clásica, aparecian individuados distintos agrupamientos de los institutos, en torno a ciertos intereses relevantes en la conciencia jurídica: status de los indivíduos, poderes domésticos, obligationes, successio; pero no existe un intento serio para conseguir sistematizaciones más generales. Pero una cierta sistemática no está ausente.

El mismo GUARINO observa que las sistematizaciones jurisprudenciales, de acuerdo con las grandes obras clásicas son: la civilistica (sus primeros brotes se remontan a la Ley de las Doce Tablas y a los comentarios de los juristas preclásicos, siendo su fundador QUINTO MUCIO y alcanzando su perfección en SABINO); la sistemática edictal (formada lentamente a través de los edictos de los magistrados, especialmente de los pretores urbanos; esta sistemática fue aceptada por juristas como PAULO, ULPIANO y GAYO y, antes de ellos, por los autores de las colecciones de quaestiones y responsa); y la sistemática institucional (la más sensible de las exigencias de sintesis y al encuadramiento lógico de los temas). La más famosa sistemática, y la que tuvo más influencia en los juristas posteriores, fue la de las Institutiones de GAYO, resumida por él mismo en estos términos: "omne ius quo utimur, vel ad personas pertinet, vel ad res, vel ad actionesw(26).

Sin embargo, no existió en Roma una ordenación sistemática cerrada, entendida, como en nuestro tiempo, a la manera de "rígida consecuencialidad respecto a unos principiosn. Entre los factores que hacen que este sis- 
tema no existiera en Roma, hay que señalar el hecho de que la lex supone un núcleo escaso del ordenamiento, frente a la cual el Derecho vivo tenía que discurrir por otros cauces, por la vía de la interpretatio prudentium y de la interpretación pretoria, que más que partir de normas fijadas por el legislador, van adecuando la justicia material al caso concreto(27).

Un problema importante en torno al método y las construcciones sistemáticas de los juristas romanos, es el análisis de las influencias filosóficas griegas, así como de la retórica y de la dialéctica. Algunos autores piensan que el enfoque dialéctico dado a la materia jurídica, por influjo de la filosofía griega, hace que la ciencia jurídica romana-hasta entonces disciplina técnica y práctica-se configure como verdadera ciencia jurídica(28). Con M. KASER creemos que aunque este método dialéctico (centrado en el estudio de los genera y species, utilizando la divisio y la differentia) contribuyó a aclarar los conceptos, los romanos conocieron ya antes la elaboración de reglas generales y, por otra parte, "se mostraron mucho más retraídos de lo que pueda creerse»(29), a la hora de elegir y utilizar ese método.

En cualquier caso, parece exagerada la posición de LA PIRA(30), porque su empeño en demostrar que la influencia griega en la sistemática romana fue decisiva no parece del todo convincente.

Por último, parece evidente que el estudio de la lógica propia de los juristas romanos, así como de la personalidad y mentalidad de cada uno de ellos, puede abrir nuevas perspectivas en el conocimiento del Derecho romano(31). Esta última idea, hoy bastante común entre los romanistas, ha venido a centrar el interés de los especialistas a partir de las afirmaciones de SCHULZ en sentido contrario(32). Considera exagerada la expresión de SAVIGNY cuando se refiere a los juristas romanos con la calificación de "personalidades fungibles", ya que es evidente que existen entrẹ ellos diferencias en la forma de exposición y en la autonomía del pensamiento. Pero entiende que se pueden señalar particularidades lingüísticas de éste 0 aquel jurista, enumerar las doctrinas que uno u otro han hecho progresar, pero todo esto no modifica la constatación de que en el método de la Jurisprudencia romana no existen transformaciones, que el lenguaje jurídico permanece constante, en conjunto, hasta la mitad del siglo III d. C. y que, en suma, la individualidad científica está poco desarrollada(33). 
En realidad, el estudio detenido de cada uno de los juristas romanos, a partir de la obra de KUNKEL sobre el origen y la posición social de los mismos(34), va eliminando las ideas erroneas en este campo importante de la romanistica. Igualmente, debe hacerse mención especial de aquellas investigaciones que abordan el lenguaje de los juristas romanos y la terminología específica usada para elaborar los conceptos jưrídicos(35).

En suma, si es cierto que la ciencia jurídica fue la forma de creación más espontánea y durable del pueblo romano, lo es también que sus jurisconsultos representan el tipo ideal en su orden. A ellos se deben, entre otras cosas, las siguientes: 1) la fijación de los conceptos básicos del pensamiento jurídico; 2) un análisis profundo de las relaciones humanas y el aislamiento de los elementos jurídicamente esenciales; 3) la creación de un vocabulario técnico preciso y la elaboración de gran parte de los métodos constructivos (es decir, todos los instrumentos que constituyen el patrimonio más valioso de los juristas a lo largo del tiempo). A esto se añade la armonía entre las exigencias del progreso jurídico con la estabilidad de principios que es necesaria para la construcción de un sistema unitario, asi como un perfecto equilibrio entre la teoría y la práctica del derecho.

\section{2.-CIENCIA E HISTORIA EN EL CONOCIMIENTO DEL DERECHO: EL DERECHO ROMANO COMO DERECHO HISTORICO}

A.-El Derecho Romano pertenece, hoy, sin duda, al campo de la historia jurídica: es un derecho histórico y para el investigador se presenta su estudio como Historia del Derecho. Los estudios histórico-jurídicos constituyen, entre las ramas de la cultura moderna, un punto de llegada, en el sentido de que se han ido desenvolviendo a lo largo de los últimos siglos rdel desarrollo de la Jurisprudencia o saber jurídico.

La actitud histórica frente al Derecho tiene raíces antiguas. MASCHI(36) ha profundizado recientemente en este problema, estudiando los distintos aspectos en que se manifiesta la sensibilidad de los antiguos hacia el devenir del Derecho. En la época clásica, la relación entre ciencia e historia supuesto que ésta no se entiende sino es como tradición, como 
valoración de lo precedente, como utilización consciente del pasado, existe una crítica que toma de ese pasado el objeto de su propia investigación y el motivo último para valorar el presente. No es concebible la ciencia sin la conciencia de que los datos de la tradición son el producto de una experiencia que se remonta en el tiempo hasta los orígenes. Si la jurisprudencia alcanza a concebir el derecho vigente como unidad espiritual, es evidente que esta unidad no significa, como se ha pretendido, una negación de la historią, al contrario, esta valoración del pasado y la crítica que de él se realiza aparecen como las actitudes más relevantes de los mayores ingenios y usi riscontrano-proprio come posizione mentale dominante-in giuristi sia della giurisprudenza preadrianea che di quella successivas(37).

Refiriéndose a las enunciaciones histórico-programáticas de los juristas clásicos, estudia, en especial, a POMPONIO, cuyo programa inicial se encuentra al comienzo del Liber Singularis Enchiridii: "necessarium nobis videtur ipsius iuris originem atque processum demonstrares(38). Esta enunciación de POMPONIO-comenta-está en consonancia con la impostación histórica de una edad consciente de las exigencias de un pensamiento, que reflexiona sobre los factores esenciales de una civilización en la cual el fenómeno jurídico viene a ser la expresión más alta. Este método es típico del pensamiento clásico más evolucionado, no exclusivo de POMPONIO(39).

Posteriormente, los humanistas comenzaron a ver interpolaciones y a ejercer crítica historica en el Corpus luris Civilis, al que, por tanto, comenzaron a mirar como fuente histórica. Toda la Edad Media había considerado estas fuentes romanas como fuente normativa de donde brotaba el.saber jurídico único, con una autoridad parangonable al saber teológico que emanaba de los Libros Sagrados. Jurisprudencia y Teología se desenvolvieron como métodos paralelos. Los comentarios de los Doctores seguían el orden legal del Digesto y tenían un carácter de vinculación al texto, que únicamente los comentaristas comenzaron a superar, si bien el comentario vinculado al orden legal perduró hasta la Edad Moderna.

El nacimiento de la historia jurídica es un aspecto de la historia misma de la jurisprudencia europea o continental. FUENTESECA, entre otros, ha descrito(40) el proceso de diferenciación entre Historia y Dogmática 
como característica de esta Jurisprudencia. En su desarrollo histórico, dio lugar, por una parte, a la creación de la Historia del Derecho como ciencia historiográfica $y$, por otra, al cultivo exageradamente dogmático del Derecho. Desde el siglo XIX se vió en el cultivo dogmático del Derecho, por parte de la mayoría de los juristas, el ideal de la verdadera ciencia jurídica. El autor piensa que el puente que salvará el abismo entre Historia y Dogmática, "únicamente podrá lograrse con el convencimiento de la historicidad misma del derecho positivo en el sentido de que éste se halla condicionado siempre por el pasado más o menos inmediato, por su vinculación a las circunstancias historicas»(41).

El nacimiento de la historia jurídica es un fenómeno profundo en la evolución del derecho europeo. Ni la descripción del cultivo del derecho en Roma realizada pon POMPONIO, ni otros trabajos de este género, constituyen, para muchos romanistas, una verdadera historia juridica. Tampoco lo es, sin duda, la critica de los humanistas. La auténtica historia jurídica nació con la Escuela Histórica, estudiada, y valorada, por ejemplo, por ORESTANO(42), ROSS (43) y otros.

Esta escuela afirma, sustancialmente, que el Derecho es producto de la ciencia popular (Volkgeist) y se ordena a la satisfacción de las necesidades propias de esta conciencia. Es, pues, un hecho esencialmente histórico, en contínua evolución. Espontáneo en su origen y en sus cambios, está íntimamente ligado a todos los otros fenómenos históricos y sociales y a las actitudes peculiares de cada pueblo, al que acompaña en sus transformaciones. No existe un derecho eterno e inmutable que pueda ser deducido a priori de la razón, de igual modo que no existe una lengua racional y arbitraria. La Ley debe reconocer y acuñar lo que la conciencia popular o espiritu del puieblo ha elaborad. De aqui se deduce la escasa función creadora del Estado y el reconocimiento de la costumbre como fuente genuina y, en cierto sentido, única, del Derecho. El Estado, en cuanto legislador, y la clase de los juristas en cuanto elaboradora del Derecho son vistos como órganos e intérpretes de esta conciencia popular(44).

Aunque no llegó a sacar las últimas conclusiones de estos postulados teóricos, puede afirmarse que la Escuela Histórica ha dado su verdadero sentido a la Historia del Derecho. A partir de entonces comenzó el 
cultivo de las dos grandes ramas de la historia jurídica continental: el Derecho Romano y el Derecho Germánico, así como estudios aislados en torno a los diversos derechos nacionales. En realidad, hablar de Historia del Derecho como algo sustancialmente jurídico en sí, no tenía sentido hasta la aparición de la Escuela Histórica. El lusnaturalismo racionalista concebía al Derecho como producto de la razón, veía en él un sistema de conceptos lógicamente elaborados en cuya arquitectura racional se creía realizado el ideal de la ciencia jurídica. En el fondo de esta concepción estaba latente el principo de autoridad del texto romano: se veía todavía en el Derecho Romano la ratio scripta y se pretendia reelaborar sus normas hasta la máxima perfección para convertirlas en principios racionales de validez universal.

Precisamente por este afán de racionalización de la materia del ius privatum, la disposición sistemática de ésta se habia alejado enteramente del orden de comentario legal. A lo largo de los siglos XVII y XVIII se ensayaron diversos órdenes sistemáticos, si bien la definitiva fue la establecida por THIBAUT y HEISE. EI ius privatum quedaba estructurado de este modo: Parte general, Derechos reales, Obligaciones, Derecho de familia, Derecho hereditario e In integrum restitutio. Esta ordenación sistemática fue admitida por los mismos representantes de la Escuela Historica, pasando asi a toda la Pandectística. La Escuela Histórica, a pesar de su reacción contra el lusnaturalismo racionalista, admitio una sistemática que llevaba la impronta de signo contrario. Sus adeptos trabajaron en conexión con la corriente historicista, pero no renunciaron al racionalismo, excepto en el caso de manifiestas exageraciones(45).

A partir de aquí, el Pandectismo llevará el impulso sistemático, generalizador, hasta los límites más extremos, operándose así «una especie de petrificación formalistaw(46). La Dogmática terminó siendo la verdadera expresión de la ciencia jurídica. Una última manifestación de esta tendencia es el Positivismo legal, de cuya crisis se habla en nuestro tiempo.

El cultivo histórico del Derecho siguió diversas tendencias. En cualquier caso, toda la literatura acerca de la llamada "crisis del Derecho Romanon no es otra cosa que la conciencia de alejamiento entre los estudios histórico-romanísticos y el cultivo de los derechos vigentes. 
La Historia del Derecho puede definirse como estudio de las fuentes jurídicas sin finalidad normativa. En este sentido, debe adoptar los métodos de las ciencias históricas. Ahora bien, este cultivo de la historia jurídica sigue siendo ciencia del Derecho o actividad jurídica, dado que el Derecho es precisamente la finalidad de la investigación. El Derecho Romano es, por tanto, una investigación histórico-jurídica, y sus fuentes son estudiadas como documentos históricos.

B.-En la progresiva diferenciación entre los estudios dogmáticos y los históricos en el campo jurídico, pueden distinguirse una serie de etapas sucesivas. Ciñéndonos al campo del Derecho Romano, las orientaciones de la romanística pueden agruparse en tres bloques principales:

-la dirección histórico-dogmática, que trata de alcanzar un conocimiento de la historia juridica-separando cuidadosamente los aspectos jurídicos de la fenomenología social-, con el criterio constructivo, sistemático y ordenador que caracteriza a los estudios dogmático-jurídicos. Aunque acepta el desdoblamiento entre ciencia e historia, esta dirección intenta no sacrificar la consideración histórica a las exigencias de la otra "ciencia" paralela. Pero cuando se estudian en concreto sus procedimientos, aparece claro que los modos con que el estudio histórico quiere afirmar su carácter científico no tienen un fundamento propio, sino que consisten en una imitación tanto de los procedimientos de la ciencia, como de los procedimientos que están en uso en las otras disciplinas históricas, adaptados, de algún modo, a los temas que son objeto de su investigación. Esta forma de proceder es propia, por ejemplo, de BETT|(47). Según él la unidad del fenómeno jurídico conduce al descubrimiento de correlaciones, concatenaciones, relaciones constantes de la experiencia jurídica en sus perennes mutaciones y confiere valor cognoscitivo al estudio de la historia de la fenomenología jurídica. Esta dirección y método, tuvo como expresión el denominado método histórico-dogmático, que algunos romanistas consideran todavía el método ideal para el estudio científico de la Historia del Derecho.

-el positivismo y el sociologismo en la cultura europea repercutieron en los estudios histórico-jurídicos, dando lugar a la dirección sociológica. Como señala ORESTANO(48), aunque se distingue de la Sociología en cuan- 
to su objeto sigue siendo esencialmente la Historia del Derecho, esta dirección se diferencia de la precedente "per una più spiccata tendenza, anzichè verso la costruzione dommatica dei dati della storia giuridica, verso la conoscenza del suo svolgimentox(49). Se trata de descubrir las leyes históricas del desenvolvimiento jurídico, el nacimiento, crecimiento y cambios, de los institutos jurídicos, como si fueran organismos vivos. Los datos son como materiales de observación para una construcción jurídica de grandes líneas históricas, sintéticas, siempre más generales y abstractas, que llevarian a una teoria general de la evolución jurídica. Esta ilusión de individualizar las leyes de la vida del derecho se ha ido desvaneciendo lentamente, siendo una de sus expresiones más típicas los estudios de DE FRANCISC|(50), el cual, por otra parte, ha superado posteriormente sus posiciones.

Hay que observar que la orientación sociologica, pese a todo, ha aportado un patrimonio común que en modo alguno puede ser menospreciado por los romanistas. Por otra parte, el declive de esta dirección sociológica y la superación de su intento utópico de individualizar a través de las "constantes" de la fenomenologia las "leyes de la vida del Derecho", dejaba abierto el problema de la posibilidad de un conocimiento histórico de éste que tuviera el valor de "ciencia", así como el problema del fin de estos conocimientos.

- la tercera dirección en que se han ido desarrollando los estudios históricos del Derecho es la historiográfica, que asume diversas formas; por un lado conduce a investigaciones meramente eruditas y, por otro, intenta elevarse a "historia de ideas", considerando la Historia del Derecho como una de las historias particulares en que puede y debe actuarse la Historia en general, según expresión de PARADIS|(51). ORESTANO afirma que esta orientación ha sido preparada por una larga historia, confluyendo en ella diversos componentes especulativos que tienen en común el afán de superar el problema de la "cientificidad" del estudio histórico del Derecho.

Creemos, sin embargo, que lo que ha ocurrido en realidad es que entre el cultivo dogmático de los derechos vigentes y el cultivo de la historia jurídica se produjo la ruptura a que hemos aludido anteriormente, siendo 
la consecuencia de esto el hecho de que los historiadores no tuvieron más opción que continuar depurando sus métodos cada vez más cerca de las ciencias históricas. Una justificación filosófica de esta situación puede encontrarse, por ejemplo, en el pensamiento de CROCE, que identifica filosofía e historia.

Este acento crociano puede percibirse claramente en algunos romanistas italianos como LAURIA, CARRELLI, GUARINO(52). CARRELLI sostiene la validez de los estudios romanísticos en sí mismos, porque lo histórico es válido independientemente de su utilidad. En tanto un hombre moderno, según dice este autor(53), pueda sentir un problema del pasado con la misma inquietud de un problema vivo, no habrá crisis en los estudios histórico-críticos.

A nuestro juicio, es preciso volver a unir ciencia e historia dentro del conocimiento jurídico: es decir, la ciencia jurídica debe integrar la consideración histórica de modo que ciencia e historia vengan a ser como "termini inscindibili della conoscenza giuridicaw(54).

En suma, el estudio del Derecho romano-y su enseñanza-debe hacerse de acuerdo con las exigencias de la ciencia contemporánea, considerándolo como un derecho histórico, sin vigencia en nuestro tiempo. Y supuesto que en el pensamiento jurídico actual se va afirmando la convicción de que la noción de Derecho tiende a resolverse en la experiencia jurídica, el estudio histórico del Derecho aparece en realidad como estudio de la experiencia jurídica(55).

Esta forma de afrontar el estudio histórico del Derecho constituye el terreno más apto para el encuentro teórico de múltiples direcciones del pensamiento; este es el único modo de que disponemos para considerar el Derecho sin ninguna exclusión o amputación de su fenomenología, en cualquiera de sus manifestaciones concretas o de sus determinantes, haciendo posible un conocimiento integral e insertándole en la realidad de la vida (en su concreta dimensión histórica).

Un estudio de la Historia jurídica concebida como Historia de la experiencia jurídica lleva necesariamente a considerar algunas manifestaciones de tal experiencia en la totalidad de sus conexiones con lo real his- 
tórico y, por tanto, a uricercare le reciproche implicazioni tra i fenomeni "giuridici" e la struttura delle società in cui essi si manifestanow(56). Más aún, para entender la índole y la eficiencia del ordenamiento jurídico de una sociedad es preciso, según observa lúcidamente DE FRANCISC|(57), considerar los varios ordenamientos que coexisten y actúan entre sí, interfiriéndose y condicionándose todos, a través de los contrastes, a la vida del ordenamiento social. Pretender captar el Derecho en su fenomenologia prescindiendo del estudio del ambiente en que nace y de la existencia de otros ordenamientos, esto es, sin tener en cuenta el análisis de las diversas fuerzas espirituales que-según los tipos de sociedad-contribuyen a organizar un pueblo, sería como pretender conocer un organismo limitándose a estudiar su morfología o anatomía y dejando a un lado la biología, la bioquímica, la fisiología y la ecología, que son las fuerzas físicas y químicas y las situaciones ambientales que condicionan la vida.

En un importante estudio de MOMIGLIANO en torno a la renovación de la historia de los derechos antiguos(58), se señala cómo, sean cuales fueren las causas de la eliminación de la Historia del Derecho como historia independiente, lo cierto es que éste, en cuanto sistematización de relaciones sociales, es incomprensible sin el análisis previo de las ciencias ético-religiosas, de la producción económica, de las fuerzas militares y de las orientaciones sexuales propias de una sociedad. Quizá pudiera pensarse que la historia de la literatura o del arte o de la religión, pueden conservar todavía una cierta autonomía en cuanto radican en diversas actividades de los individuos, pero no puede pensarse en una autonomía de la Historia del Derecho que es, por su naturaleza, una formulación de relaciones sociales que radican en múltiples actividades humanas. $Y$ si en algunas existe una clase de jurisconsultos con especiales reglas de conducta y de razonamiento también éste es un fenómeno social que debe ser interpretado(59). El autor descendiendo a consecuencias de carácter práctico señala que es evidente que la presente situación de la investigación histórica exige que todo historiador sepa entender el Derecho del mismo modo que debe conocer la economía, la religión o la política. Evidentemente, esta exigencia lleva necesariamente a la reforma de la enseñanza universitaria de la Historia. Una errónea interpretación de hechos económicos o religiosos 
puede fácilmente ser la causa de una interpretación equivocada de hechos jurídicos, y viceversa.

Refiriéndose explícitamente a esta misma problemática, GARCIAGALLO observa que bajo la inspiración de la dogmática jurídica, la ciencia de la Historia del Derecho, ha delimitado su campo para ocuparse sólo del Derecho, con exclusión de cualesquiera otros elementos. Pero-añadela "purificación de lo jurídico" ha llevado a excluir de la Historia del Derecho toda consideración sobre las situaciones que el Derecho regula, de tal modo que se convierte en una historia de conceptos y normas abstractos y formales, sin contacto alguno con la realidad(60).

\section{3.- EXPERIENCIA JURIDICA Y CIENCIA DEL DERECHO: HACIA UNA CONCEPCION NO INSTRUMENTAL DEL DERECHO ROMANO}

Aunque en nuestro siglo la ciencia del Derecho Romano-una vez desaparecida la necesidad de aplicación directa de los principios juridicos romanos - ha pasado a ser üna rama más de las ciencias históricas, algunos romanistas continúan resistiéndose a admitir este cambio de orientación. Esta actitud se explica, en parte, teniendo en cuenta la tradición multisecular que ha considerado el estudio histórico del Derecho Romano como un auxiliar más de un estudio esencialmente práctico y finalístico del Corpus luris. Además, y hablando de forma general, el estudio del Derecho Romano-como derecho histórico-no interesaba tanto por sí mismo como en función de unos determinados fines, intereses 0 aplicaciones concretas(61). En fin, se ha llegado a interpretar la "historificación" de los estudios romanísticos como una desviación, como un exceso que priva al Derecho Romano de la función que ha ejercido durante siglos en la formación y guía del pensamiento jurídico europeo, aislándolo de la vida presente y quitándole cualquier posible interés para los juristas actuales. En este sentido, la orientación histórica del Derecho Romano es considerada incluso como una de las causas de la "crisis" del Derecho Romano.

Sin embargo, es posible entender las razones que avalan a aquella otra orientación de la romanística que prefiere considerar el Derecho ro- 
mano como el conjunto de la experiencia juridica romana, superando la pretensión (tan arraigada a lo largo de los siglos) de interpretar el Corpus luris únicamente como un sistema normativo que ha dado lugar a una serie de experiencias sucesivas a través de un amplio y complejo proceso de evolución. ORESTANO ha observado que si calificamos como "Derecho Romano" el conjunto de experiencias particulares que se han sucedido en el tiempo, no sólo se hace imposible una conceptualización apropiada de lo que realmente fue la experiencia jurídica romana en si misma, sino que tampoco es ya posible entender lo que han sido realmente los desarrollos del derecho y de la ciencia jurídica desde JUSTINIANO hasta nuestros días, esto es, lo que tienen de particular y propio en la Historia del Derecho y su influencia real en nuestro presente(62).

Según esto, son tales experiencias particulares-y su unión en una visión más general de la experiencia jurídica en su desarrollo histórico-las que constituyen el objeto del estudio histórico del Derecho. Pero el conocimiento de este desarrollo o evolución sólo se alcanza mediante el conocimiento de cada uno de los complejos de experiencias que lo componen. En otras palabras, el conjunto de estas experiencias constituye lo que llamamos tradición romanística y permite establecer una clara demarcación entre la experiencia jurídica romana y las experiencias sucesivas a lo largo del tiempo.

Es evidente que este planteamiento lleva consigo una actitud crítica respecto a las concepciones mantenidas por la Pandectística, esto es, para aquella especial elaboración del Corpus luris (entendido como sistema normativo vigente) que se inició en Alemania en el s. XVIII y alcanzó su momento culminante en el XIX. Consistía particularmente en una construcción teórico-práctica del Derecho romano justinianeo, armonizado con las exigencias propias del tiempo y dogmatizado de acuerdo con la mentalidad abstracta del pueblo alemán. Aquella elaboración dió lugar a una formación que terminó adquiriendo una autonomía propia y cuya historia está conexa con la de gran parte de la ciencia jurídica moderna y del derecho positivo contemporáneo de muchos pueblos. Durante mucho tiempo esta elaboración ha sido considerada como una de las expresiones más puras del Derecho Romano.histórico, hasta el punto de llegar prácticamente a identificarse. 
Este hecho ayuda a comprender las razones por las que el estudio histórico del Derecho Romano ha encontrado una gran dificultad, en una lenta y dura conquista de su objeto63), superando la llamada "concepción instrumental del estudio del Derecho Romanow(64). En cualquier caso, la concepción del Derecho Romano como derecho histórico tiene un particular significado dentro de la romanistica actual, que trasciende el campo específico de esta disciplina y se inserta en el cuadro de las orientaciones generales de la ciencia del Derecho; por tanto, $-y$ en términos todavía más amplios-refleja de algún modo las orientaciones fundamentales del espíritu moderno(65).

\section{4.- LA ENSEÑANZA DEL DERECHO ROMANO}

A.-BADENES GASSET ha señalado que la determinación de un método adecuado en la enseñanza de las disciplinas de Facultad, es función, ante todo, de la misión que se atribuye a la Universidad(66). El tema de la misión de la Universidad ha constituido una preocupación permanente de los maestros del pensamiento y no es casual el hecho de que durante los últimos años haya aumentado notablemente la bibliografia especializada en torno a él.

Ya ORTEGA Y GASSET había llamado la atención sobre las tres funciones que debe cumplir la enseñanza universitaria: 1) transmisión de la cultura; 2) enseñanza de las profesiones; 3) investigación científica y educación de los nuevos hombres de ciencia. En este esquema, pues, la formación cultural, la instrucción profesional y la elaboración de la ciencia serían las tres metas posibles de la Universidad(67). Más recientemente LAIN ENTRALGO ha explicado cómo y por qué la misión de la institución universitaria exige el cumplimiento de los siguientes fines: 1) uno histórico: la conservación y transmisión de los saberes recibidos; 2) otro docente o profesional: la enseñanza de las disciplinas científicas; 3) otro formativo, en el sentido más amplio y humano; 4) otro de investigación: la Universidad debe aumentar el caudal de verdades y técnicas que los hombres poseen; 5) otro perfectivo de la sociedad en que la Universidad vive y se desarrolla(68). 
Admitida la complejidad de fines que deben tener su realización en la Universidad, las dịvergencias se manifiestan a propósito de la determinación de cuál de ellos debe ser el fin primordial, o hasta que punto la búsqueda de uno de ellos puede o debe posponer la obtención de los demás. Frente a la Universidad cultural, acorde con los esquemas clásicos de educación, en los últimos tiempos se concede preferencia a la necesidad de enseñar las técnicas profesionales, cada vez más complejas y apoyadas en los modernos descubrimientos científicos.

En cualquier caso, el fundamento de la enseñanza universitaria es la ciencia y, en nuestro caso, la ciencia del Derecho romano. Aunque la tarea de hacer ciencia no compete únicamente a la Universidad, la comunicación entre ésta y los Centros de Investigación debe ser constante, a fin de que ella pueda cumplir uno de sus fines esenciales: la trasmisión de la ciencia y la enseñanza de los problemas al nivel científico en que se encuentren en cada momento. A nuestro juicio el problema de los fines universitarios debe resolverse en la sintesis de una formación cultural y humana que conjugue al mismo tiempo una preparación exigente para el ejercicio de las profesiones y la posibilidad real de una dedicación a la investigación científica.

Según GUASP, saber el Derecho es algo menos que filosofar acerca del Derecho, pero algo más que conocer las leyes concretas y su aplicación histórica. Saber el Derecho es conocer la realidad jurídica. Y el conocimiento de la realidad sólo puede proporcionarlo la toma de conciencia del cuadro de posibilidades, más amplias que esa misma realidad, y que permite precisamente explicarla e interpretarla. Lo mismo que ocurre en otras ciencias, lo que tiene que saber el jurista en cuanto tal es cómo explicar la realidad de hoy en función de las posibilidades de un sistema cualquiera: para que sepa a qué atenerse respecto a un fenómeno jurídico determinado, tiene que contar con un repertorio de concepciones situadas por encima de ese fenómeno(69).

Prolongando esta reflexión, es posible situar al Derecho en sus relaciones con el hombre y la sociedad. Las dos célebres fórmulas (ubi homo ibi societas - ubi societas ibi ius) no resultan, sin más, evidentes. De hecho en la Historia, la realidad del "orden civil» ha tenido que buscar sutiles legi- 
timaciones y la realidad del orden jurídico ha tenido que ser defendida de la acusación de ser elemento represivo e incluso tiránico. En cualquier caso, este es el contexto en que se sitúa el problema de la relación entre naturaleza y norma, que incluye las cuestiones de si la sociedad es un fenómeno "natural», y si la naturaleza social es un cosmos ordenado.

Se trata de cuestiones en torno a las cuales, dice ALVAREZ TURIENZO, "se suscitó y desarrolló el problema del Derecho natural. El Derecho natural, por "derecho", será asunto de orden social; por "natural», ese orden será reflejo de una normativa inmanentes(70). Teniendo en cuenta la problemática suscitada por el positivismo jurídico, el autor trata de orientar el conflicto de mentalidades operante en la cultura del presente. En particular hace ver cómo no se trata en absoluto de una cuestión bizantina la pregunta de si la lucha por el Derecho es un aspecto de la lucha por el hombre, o bien esta lucha por el hombre y su libertas conduce a poner en cuestión el Derecho como instrumento opresivo.

A propósito de la enseñanza teórica del Derecho Romano, es indudable la indiferencia que suscita el hecho de que se trate de un Derecho no vigente, del mismo modo que ocurre en otros campos de los estudios históricos(71). Aquí radica la necesidad de poner de relieve el carácter básico del Derecho Romano en la cultura jurídica europea(72). En este punto creemos que continúa siendo válida la posición defendida por KOSCHAKER(73), debiendo insistirse especialmente en la proyección del Derecho Romano en Europa y subrayando la significación del Derecho Común y del Derecho de Pandectas. En este sentido no debe perderse de vista el hecho de que es posible-y algunas veces necesario-recurrir a la exposición de una institución desde Roma hasta la Pandectística, tal como aparecen en algunas investigaciones de influencia koschakeriana. Con ello se iría derivando hacia una corriente que impulsa a ver los estudios romanísticos en la línea de Historia del Derecho Privado que, en el fondo, no contradice su raịgambre histórica.

FUENTESECA ha señalado que la solución romana ha sido el nervio de la institución de una evolución singular y que sigue pesando con la fuerza decisiva de lo histórico, del mismo modo que otras creaciones históricas son parte integrante del acervo cultural de Europa(74). La "Dogmen- 
geschichten, desde un punto de vista científico, reanuda la antigua simbiosis entre historia y dogmática separadas desde el siglo pasado, y en este sentido la experiencia histórico-dogmática reanuda la doble vertiente de los estudios jurídicos. Ya no se trata de una exaltación romántica de la supervivencia del Derecho Romano a través de los Códigos actuales, sino de una visión superadora e integradora a la vez de los estudios dogmáticos e históricos(75)

B.- Otra idea que debe orientar la enseñanza del Derecho romano (de igual modo que debe presidir la exposición e interpretación de la historia del Derecho en general) es que el Derecho es en realidad expresión del espíritu del hombre en la organización social de la vida humana. Cuanto realiza el hombre en la propia existencia relacional (con su pensamiento, pasiones, luchas y esperanzas) se refleja en el Derecho y, a su vez, recibe de él ejemplo y freno, en un ciclo histórico en el cual -dice $B$. PARADISI-no hay supraestructura y substratos, sino sólo el espíritu del hombre y las innumerables creaciones de su devenir(76).

La historia jurídica debe ver en su propio objeto el reflejo de intereses económicos, de preocupaciones morales y de los ideales culturales propios de cada época. En el caso del Derecho romano, la política, la economía, la religión y la cultura tienen que ver directa o indirectamente con el Derecho y "la cuestiọn está en saber en qué medida el Derecho, referido a tal realidad-la realidad social-es justow(77) .

Más en particular, creemos que en la distribución del curso de Historia e Instituciones de Derecho romano, es necesario prestar especial atención a la historia constitucional de Roma. En efecto, no se pueden conocer bien las instituciones juridicas sin un claro conocimiento de la estructura del Estado romano. A. D'ORS habla de un usincronismo entre Historia Constitucional e Historia del Derechos(78). A la evolución de la constitución política romana hay que referirse necesariamente al tratar de las fuentes creadoras del Derecho romano, lo mismo que al analizar el sistema procesal que le es propio(79).

Esta profunda inserción del Derecho romano en la realidad social (entendida en su sentido más amplio, esto es, en cuanto engloba en sí la vida política, los hechos económicos y las relaciones culturales) no sólo expli- 
ca por qué se encuentra en las fuentes jurídicas un caudal tan grande de experiencia histórica(80), sino que ofrece también la clave de su presencia en la conciencia jurídica moderna. Un ejemplo eminente de esta presencia es, sin duda, el principio de que el hombre libre, en cuanto tal, es sujeto de derechos, principio que constituye un elemento fundamental de los ordenamientos modernos de Derecho privado. CHIAZZESE explica cómo este principio constituyó el término de una larga y fatigosa evolución. De hecho, se habia partido de una norma bastante distinta: según el antiguo ius Quiritium solamente el civis era sujeto de derechos privados. Posteriormente el principio quiritario fue transformándose como consecuencia de una serie de factores y circunstancias. Influyeron el ius gentium y el ius honorarium, la progresiva extensión de la ciudadanía, la disgregación de la familia agnaticia, la filosofía estóica, la ética cristiana, la decadencia postclásica del ius civile y la prevalencia del ius gentium. Ciertamente, en el Corpus luris el principio según el cual se reconoce directamente al hombre libre la cualidad de sujeto de derecho privado, está sancionado de forma vigorosa. Tal principio suponía el rechazo de cualquier distinción de castas o cualquier situación de privilegio entre los hombres pertenecientes a una determinada comunidad política; reconocía la personalidad patrimonial y procesal de los filiifamilias; liberaba a la mujer de cualquiera sujeción jurídica y preparaba, en fin, la emancipación de los esclavos. Tal reconocimiento de la personalidad humana adquiere una importancia tan grande en la historia del pensamiento jurídico que ha sido considerado por muchos como el motivo fundamental de la universalidad del Derecho romano(81).

Resulta obvia la significación actual de esta conquista dentro del sistema de derecho privado de los pueblos más civilizados, que se apoya justamente en este reconocimiento de la personalidad humana, en cuanto tal, y en el relieve que se otorga a la libre voluntad de los indivíduos como fuerza creadora de efectos jurídicos.

Pero en el Corpus de las leyes romanas los modernos han encontrado también una defensa sólida de sus libertades políticas y civiles, en cuanto que la expansión del Derecho romano en el mundo moderno ha seguido la vía de la libertad, esto es, aquella misma vía que habían elegido los juris- 
tas republicanos cuando el sistema romano de derecho privado se formó y consolidó, rechazándose cualquier forma de monarquía absoluta o de dictadura permanente. No en vano la idea del dominus, del rex y del tyrannus encontraron siempre un abierto rechazo en los espíritus romanos. Incluso aquellos que alcanzaron de hecho el poder supremo, como CESAR o AUGUSTO, no aceptaron nunca ser llamados domini o ser coronados como reyes. En este contexto se explica por qué CICERON pudo escribir: omnes nationes servitutem ferre possunt, nostra civitas non potest(82). Esta concepción fundamental anima internamente todo el sistema del derecho privado, que está dominado por la idea de que la intervención estatal en la vida de los indivíduos debe mantenerse dentro de límites muy restringidos y que, por el contrario, debe garantizarse a los cives el margen más amplio posible de autonomia jurídica.

Esta idea, tan profundamente connatural al espiritu romano, aunque nunca fue fijada expresamente en normas de derecho escrito, está contínuamente presente en toda una serie de institutos fundamentales, desde la potestad familiar al régimen contractual, desde la propiedad hasta las sucesiones. En otras palabras, en la Roma republicana el reconocimiento de las libertades políticas y civiles no condujo a especulaciones teóricas, sino que es una forma de vida, una costumbre, un sentimiento firme e inalterable(83).

Cuando posteriormente el Cristianismo reconoce por primera vez a la persona humana una dignidad suprema que le viene directamente de Dios y que entraña necesariamente la substracción de la vida del espíritu a cualquier forma de control o dominio estatal, se lleva a su término el ideal que ya estaba presente, aunque de forma imperfecta, en la conciencia juridica y en la praxis romana de la libertad(84).

C. - Como toda actividad docente, la enseñanza del Derecho Romano supone la comunicación o transmisión de unos conocimientos científicos o de unas técnicas que se basan en estos conocimientos, hecha por un profesor y dirigida hacia unos alumnos. En la estructura de esta actividad de enseñanza se encuentran, así, tres elementos: el maestro, el alumno y la propia comunicación que se establece entre ellos. Ningún planteamiento metodológico puede olvidar uno de estos tres elementos concurrentes, 
así como es indudable que toda reflexión que se haga sobre estos problemas no puede desconocer la situación real de la Universidad en cada momento histórico y en cada país en particular, supuesto que existe una conexión profunda entre Universidad y Sociedad.

No se trata solo de transmitir los resultados de las investigacienes, sino que debe presentarse al estudiante, en expresión de U. ALVAREZ, "el verdadero panorama interior de la ciencia, cuajado de problemas matrices aún no definitivamente resueltos y necesitados todavía de una revisión e investigación posterior (38). Una de las condiciones esenciales para conseguir este tipo de enseñanza es la capacidad de leer críticamente las fuentes. GUARINO ha manifestado recientemente su disconformidad con el modo acrítico de citarlas, según una costumbre bastante difundida pero que debe ser abiertamente rechazada(86). En igual sentido se pronuncia NOCERA; según él, parece como si la fuente sirviera sólo-y dentro de los límites únicamente en que es indispensable como referencia canónica-para cohonestar una tesiś o un tratado más o menos académico87). Por otra parte, debe reconocerse que la gradual reducción de las fuentes por parte de algunos romanistas a un rango inferior, no hace justicia a la moderna concepción de la cultura como historia total de la civilización.

Estamos de acuerdo con el autor cuando señala que el genuino trámite entre adultos y jóvenes no puede ser un vademécum, un beadeker cultural-escolástico, más o menos puesto al día, donde estén señalados y prefigurados los límites alcanzados-o que hay que alcanzar-, como si fuera de ese vademécum y de esos límites todo fuera oscuridad, vacio y caos.

Por el contrario, parece llegado el momento de construir un edificio cultural, en el cual el único lenguaje universal sea el de las fuentes, o sea, la capacidad de abordar directamente los procesos críticos que ponen en confrontación las palabras y las cosas para encontrar su verdadera correspondencia; no se trata sólo de la equivalencia didáctica entre el término y su semántica, sino una especie de simetría histórica, de proporción de los diferentes aspectos de la realidad como complejo de creaciones y pensamientos presentes perennemente en nuestro espíritu(88). 
Esto conduce lógicamente a la conclusión de que también el asi llamado "pluralismo de las fuentes" no significa, para los hombres de cultura, una enumeración formal y mecánica de los hechos productivos del fenómeno jurídico (como, por lo demás, de cualquier otro fenómeno), sino que tiene el valor de una investigación exhaustiva de los múltiples elementos que concurren a la fundación de un saber y de un entender tendencialmente unitario e integral. Hay que otorgar a las fuentes de que disponemos un sentido global: a través de ellas es posible una toma de contacto directo con la totalidad del ambiente y con los aspectos singulares $y$ concretos del mismo, a fin de sistematizarlos y clarificarlos. A su estudio, pues, está ligado cualquier tipo de investigación, tanto humanística como científica.

\section{5.-LA ORGANIZACION DE LA DOCENCIA: CONTENIDO Y METODOS}

\section{A.-LECCIONES TEORICAS: PRESUPUESTOS}

En la enseñanza universitaria del Derecho Romano la lección teórica diaria constituye, a nuestro juicio, un medio eficaz e insustituible de posibilitar el acceso del alumno a un conocimiento profundo, coherente y sistemático.

Por razones muy diversas-y a causa en algunos casos de actitudes antiautoritarias, de prejuicios, o bien de aspiraciones idealistas a un tipo de enseñanza radicalmente innovador-la lección magistral es menospreciada o combatida. Pensamos, sin embargo, que debidamente programada y planificada, mantiene su plena vigencia y constituye un elemento indispensable de la docencia universitaria.

El Derecho Romano es una disciplina eminentemente sistemática. Su exposición debe hacerse partiendo de este hecho e insistiendo fundamentalmente en las líneas esenciales, sin perder de vista que el conocimiento de un sistema legal es la base para cualquier posible ejercicio práctico posterior de valoración jurídica de los hechos(89).

Aunque algunos autores siguen un orden de exposición diferente(90), entendemos que para obtener una visión global, coherente de las institu- 
ciones, debe partirse de la explicación de los derechos reales antes que abordar la problemática relativa a las obligaciones y contratos. Porque si el alumno conoce lo que es la propiedad, o la posesión o el usufructo, por ejemplo, podrá calibrar mejor las múltiples posibilidades que ofrecen los modos de ob́ligarse; y si ya tiene una información procesal suficiente, podrá comprender mejor los diversos modos de aquilatar la responsabilidad contractual a la hora de su actuación procesal. Esto supuesto, tendrá lugar la explicación del derecho familiar y hereditario en toda su complejidad, y finalmente, la herencia y los legados.

La experiencia docente nos ha demostrado que el Manual continúa siendo un instrumento muy apropiado para la iniciación y organización del estudio del Derecho Romano. Evidentemente, no se trata de propiciar únicamente el aprendizaje memorístico de los temas; la repetición mecánica de su contenido impediria una profundización personal del alumno y constituiria, a la larga, un esfuerzo inútil e innecesario. Por este motivo, a la exposición del profesor debe acompañar siempre la participación directa del alumno, mediante la búsqueda de aclaraciones de los puntos más importantes, o la ampliación de los contenidos expuestos, o la relación con otro tipo de problemas o temáticas afines.

El Derecho Romano constituye una disciplina singularmente apta para la práctica de la metodología interdisciplinar, tanto cuando se trata de su estudio e investigación como-tal es el presente caso-de su enseñanza(91).

Porque, en cuanto Derecho histórico, es también válida para él lo que hoy se dice de la obra literaria, o del arte, o de la economia, o de las ciencias, a saber, que debe considerarse ya superada la etapa historia-relato; la concepción de realidad histórica como un conjunto estructural, no permite separarla en compartimentos estancos: historia social, económica, jurídica, literaria, científica(92).

La tendencia actual es hacia la búsqueda de una síntesis de aquellas disciplinas que concurren, por su complementariedad, a recomponer la unidad compleja de la realidad. En el caso del Derecho-y como ya hemos señalado anteriormente-es evidente que aparece estrechamente vinculado con la política, la religión y la cultura, en cuanto modos específicos de 
reaccionar ante nuestro destino humano(93). En nuestro tiempo, hay un acuerdo tácito general en que el estudio del futuro del hombre tiene que ser interdisciplinar y que se deben tener en cuenta todos sus aspectos sociológicos, sociales e históricos al elaborar cualquier posible nuevo sistema de valores(94).

La dificultad de la enseñanza interdisciplinar proviene del hecho de que exige necesariamente el trabajo en equipo o "team teaching»(95), difícil de conseguir en la actual situación de los estudios universitarios, supuesta la configuración de los planes de estudio, los problemas de personal docente y los medios de que se dispone. Esto no impide que el trabajo interdisciplinar constituya una meta deseable y que en situaciones especiales (Colegios Universitarios, trabajos especializados con grupos reducidos...) pueda intentarse y ser llevado a efecto con eficacia.

Un criterio que debe presidir las clases teóricas, sea cual fuere el método que se adopte, es que lo fundamental no es enseñar demasiadas cosas, sino enseñar a fondo lo que se enseña(96). En el caso del Derecho, la enseñanza universitaria tiende directamente a la formación profesional de los juristas, por lo que ha de dar a los alumnos los principios formativos suficientes para la especificación del conocimiento científico. Esto entraña necesariamente, como ha observado SANCHEZ DE LA TORRE, una atención permanente a "la formación universal del jurista»(97), que implica necesariamente una serie de conocimientos sociológicos y éticos, fácticos y normativos, facilitando el contacto de la docencia académica con la cultura socializada y con los problemas generales de la comunidad(98). Además del saber especulativo, cuyo fin es la "verdad", es esencial vincular éste al saber práctico o verum relatum ad opus. Por eso, tanto el investigador como el docente debe tener unas determinadas cualidades indispeńsables; piénsese por ejemplo en el ámbito de la observación, que enseña a contar con los resultados erróneos y a servirse de los instrumentos de contrastación; o en la imparcialidad de espíritu, evitando prejuicios o dogmatismos; o en el rigor del análisis y de la crítica, que permite discernir lo importante o decisivo de lo accesorio, etc. Todas estas cualidades son también, en el caso del alumno, la condición de posibilidad para que pueda alcanzar una formación jurídica-y en lluestro caso romanistica-que ponga de manifiesto su madurez universitaria. 


\section{B.-ENSEÑANZAS PRACTICAS}

Al lado de las clases teóricas, las llamadas clases prácticas mantienen hoy su singular imiportancia e interés. No sin razón se ha señalado como uno de los defectos de nuestras enseñanzas jurídicas-y en general de todas las enseñanzas universitarias-el excesivo carácter teóricc de las mismas, a diferencia de otros pueblos en que el estudio tecrico cuantitativamente menor, se completa con ejercicios prácticos que contribuyen a adiestrar al futuro jurista en la labor material de confección de instrumentos jurídicos, forzándole a resolver problemas de la vida real, tal como suelen presentase.

En la resolución de casos-y supuestas las lecciones teóricas previas - el fragmento del jurista romano constituye el modelo de aquella forma mentis que corresponde al auténtico jurista; porque es el módulo universal que revela, sin lugar a dudas, el genio jurídico de los romanos. El Digesto proporciona una cantera riquísima de supuestos que permiten plantear casos prácticos de muy diversa índole, poniendo de manifiesto la aptitud del Derecho Romano para hallar principios y soluciones correspondientes a criterios de justicia y equidad para los diferentes sectores de la vida social.

En cualquier caso, entendemos que la eficacia de la clase práctica se diluiría considerablemente y veria reducida su eficacia si se impartieran en clases masivas, ya que se haría prácticamente imposible mantener la tensión que exige el esfuerzo de aproximación a la realidad compleja que se contempla. Deberían, pues, impartirse estas clases a grupos reducidos (de quince a veinte alumnos). Como guía orientadora para esta clase de ejercicios prácticos estimamos que es de gran utilidad, entre otros, el libro de GARCIA GARRIDO(99), que siguiendo la sistemática tradicional en las exposiciones teóricas, va ilustrando éstas con casos prácticos seleccionados. De esta forma se corrige el predominio del elemento memorístico que todavía domina en el estudio universitario. El asimilar un modus operandi como actitud viva y conformadora de la mentalidad del joven jurista, requiere una labor especial del personal docente. Pero es también la garantía de eficacia y de formación intelectual sólida. 
Parece evidente, por otra parte, que para conseguir una mayor y más profunda penetración en el Derecho Romano sería preciso un curso exegético especial, sobre todo para aquellos alumnos que no aspiran únicamente a conseguir un adiestramiento práctico o una finalidad utilitarla inmediata, sino también a una comprensión más global y abarcadora de las realidades y de los problemas. En cambio, sería suficiente un curso institucional cuando se trata de un auditorio más numeroso y menos interesado en acceder a un nivel de especialización; en este curso, además de la exposición de los institutos, sería indispensable la lectura crítica y comentada de los textos más significativos que hacen referencia a cada uno de ellos.

En todo caso, las lecciones teóricas no deben reducirse o posponerse. Es indispensable que los alumnos se penetren del sentido último que inspira la labor de los prudentes del derecho como la fuente más autorizada para dirigir el pensamiento jurídico.

Por lo demás, y aún reconociendo la relevancia que tiene en la docencia romanística el empleo del casuísmo (escuela de búsqueda de soluciones para la vida y dominio de las técnicas jurídicas), no debe perderse de vista aquella característica tan peculiar de los juristas romanos y que, según VOLTERRA, les distingue de los demás juristas de la antigüedad(100), a saber, que su forma mentis tiende siempre a la concepción y a la formulación del principio y de la regula, a la definitio y, en suma, a la construcción del sistema; y esto, aún cuando parecen ajenos a las especulaciones teóricas y a la abstracción (sobre todo cuando se les compara con los juristas modernos).

Sólo teniendo presente esta voluntad de sistematización doctrinal, este esfuerzo de elaboración teórica de los institutos y la neta individuación de la norma jurídica respecto de las extrajurídicas, aparece evidente el valor formativo de la casuistica de los juristas romanos y viene a ser, de hecho, aquel "medio vigoroso de disciplina mental» a que ha aludido BETTI en una de sus obras(101).

\section{C.-LOS SEMINARIOS ESPECIALIZADOS}

El trabajo de seminario merece, a nuestro juicio, una consideración especial, en cuanto significa una tarea de investigación llevada a cabo por 
un grupo de estudiantes en común(102). Supone que se trata de personas ya iniciadas en la disciplina y que su asistencia-nunca masiva-es voluntariamente aceptada o pedida. En realidad, se trata de la culminación del estudio universitario, y representa una oportunidad única para iniciarse en la investigación, desarrollar aptitudes y descubrir vocaciones científicas. Ciertamente, dice BADENES GASSET, "no se pueden dar reglas para investigar, como no se pueden dar reglas para la inspiración artística... el alumno guiado-y no sustituido-por el profesor, trabaja personalmente. Es él quien observa, quien experimenta, quien analiza y somete a críticas constantes el resultado de sus observacionesw(103). Entre las normas que orientan la labor de seminario hay que destacar el hecho de que el profesor elige un tema que él mismo haya investigado o que se proponga investigar personalmente, con objeto de que su labor magistral rinda al máximo y pueda controlar en todo momento las discusiones. Sobre el tema señalado se hace, en una primera sesión, una descripción del estado de la cuestión y de los fines de la labor que se inicia, aclarando cual es el estado de las fuentes y distribuyéndose trabajos concretos de investigación sobre puntos particularmente difíciles.

Cada sesión del seminario puede dividirse en tres partes: 1) una exposición sobre el tema según el orden programático de materias, con un tiempo limitado muy concreto; 2) participación de uno de los miembros del seminario con lectura del trabajo realizado; 3 ) un período más amplio de discusión. Aquí es donde el profesor puede y debe estimular la participación de los asistentes con sugerencias, orientaciones y preguntas. En cualquier caso, la labor del seminario sirve para iniciar en la técnica del trabajo científico, así como para lograr una selección del alumnado y progresivo perfeccionamiento de los más capaces.

Actualmente se insiste en que toda ponencia deberá ser seguida de discusión colectiva, con objeto de esclarecer las cuestiones dudosas y enriquecer los puntos de vista. Al final es conveniente la adopción-y en su caso la redacción por escrito-de las conclusiones concretas a que se haya llegado.

Un ejemplo concreto de la labor de los seminarios puede verse en la encuesta llevada a cabo entre los estudiantes de un seminario romanístico 
en Nápoles, bajo la dirección de A. SCHIAVONE, y centrado en torno a la tradición del Derecho Romano en la formación de algunas doctrinas del Derecho privado moderno(104).

El seminario es un medio único para preparar al futuro profesor y poner las bases para la tarea investigadora, que es una de las misiones esenciales de la Universidad. Más en concreto, interesa llamar la atención sobre el hecho de que es también el ámbito en que se programa y prepara los temas que serán objeto de las tesis de doctorado, que deben significar el comienzo o la consolidación de la madurez científica del alumno (rigor científico, dominio de las técnicas de investigación, superación de la mera erudición, uso inteligente de la bibliografía, penetración a fondo en la problemática que se contempla, desarrollo de la capacidad crítica) y una aportación original al acervo común del saber.

En este sentido-y dentro del campo concreto del Derecho Romano-es esencial el conocimiento lingüıstico y un nivel de formación suficiente que haga posible el análisis de los textos y el acceso directo a las fuentes. Sólo así será posible poner de manifiesto el verdadero panorama interior de la ciencia que, en expresión de U. ALVAREZ, está "cuajado de problemas matrices aún no definitivamente resueltoss(105).

\section{D. - SISTEMAS DE EVALUACION}

La auténtica formación universitaria exige que el alumno asuma responsablemente el propio proceso educativo. Exige también-e inseparablemente-que el profesor mantenga viva la conciencia de lo que es y significa la relación educativa, el acto de enseñar. Antes que el empleo de determinadas técnicas o métodos es fundamental el clima humano, la comunicación de las personas. Reflexionando sobre la reforma de la Universidad decía hace algunos años P. RICOEUR: «al contribuir a la realización parcial del proyecto de autorrealización del enseñado, el enseñante sigue aprendiendo y perfeccionándose; en un sentido muy real puede decirse que también él es enseñado por sus alumnos y recibe de ellos la ocasión de realizar su propio proyecto de conocimiento y de saber. Es preciso, pues, afirmar, parafraseando a ARISTOTELES que la ensañan- 
za es el acto común del maestro y del alumno. Toda posible urevolución cultural», en materia de enseñanza, se alimenta y vive de esta convicción»(106).

Si el alumno participa activamente en el sistema didáctico; si existe una verdadera comunicación entre el profesor y los alumnos, el sistema de evaluación del rendimiento académico y del nivel formativo alcanzado, ofrecerá unas garantías mayores de objetividad.

Si se tratara únicamente de enjuiciar y valorar (siempre de forma aproximada, por otra parte) los conocimientos adquiridos, el recurso a los exámenes tradicionales tiene, sin duda, una utilidad innegable, sobre todo si se trata de exámenes parciales; incluso en este último caso, está latente siempre el peligro de que el alumno pierda la visión de conjunto de la asignatura y quede el estudio del Derecho desmembrado, sin la unidad y armonía que deberían presidirlo. Pero hay algo más. Porque más allá de la posible utilidad e inconvenientes que pueda presentar el sistema de exámenes, es preciso llegar a poner de acuerdo la planificación y programación de la enseñanza, sus objetivos y métodos con el ideal formativo que se persigue en la enseñanza universitaria. Esto exige una determinación muy concreta de las fases del proceso de aprendizaje, de los contenidos que son objeto de estudio e investigación y de los fines o metas que deban alcanzarse107).

Entendemos que las pruebas de control-que pueden adoptar una gama muy amplia de expresiones-son necesarias tanto para evaluar los resultados del estudio y el rendimiento de los alumnos como para someter a crítica o revisión la metodología de la enseñanza y las orientaciones de la actitud docente (autoevaluación). En general, es indispensable fomentar el diálogo directo con el alumno, a través de los comentarios de las pruebas escritas, de las entrevistas personales, de la valoración razonada e individualizada de los trabajos realizados; más en concreto, es preciso estimular su participación activa, sobre todo en las sesiones de casos prácticos y en las reuniones de seminario. Esto supuesto, el exámen final vendría a completar los datos obtenidos mediante este sistema de control e información y ayudaría, sin duda, a matizar más el juicio global del profesor sobre la formación romanística de los alumnos. 
En cualquier caso, estimamos un factor primordial de la formación universitaria el propio principio de actividad del alumno. La enseñanza no debe sólo despertar al indivíduo y estimularlo, sino también guiar su esfuerzo y orientarlo hacia unas metas. MARITAIN ha observado que "lo que se aprende no debe ser nunca recibido pasiva o mecánicamente, como formạción que carga nuestra inteligencia. Más bien debe ser transformado activamente en la vida misma de la inteligencia y asi fortalecerlo... pero una gran cantidad de conocimientos puede sofocar esa inteligencia si quien lo recibe lo hace de manera servil; la inteligencia se siente entonces aplastada por un conocimiento que no es suyo sino de los demásw(108).

\section{6.-LA ENSEÑANZA DEL DERECHO ROMANO Y LA FORMA MENTIS DEL JURISTA CONTEMPORANEO}

\section{A.-Mentalidad pragmática y estudio del Derecho}

Parece evidente que, en la enseñanza del Derecho Romano, la elección del método y de los contenidos depende en gran medida de la concepción que se tenga de su importancia en orden a conseguir una formación básica de juristas.

Existe una mentalidad pragmática y utilitarista, muy difundida en los ambientes universitarios, que únicamente atiende al rendimiento inmediato (la solución de los casos jurídicos concretos conforme a las normas jurídicas vigentes) desentendiéndose de cualquier finalidad científica o de cualquier aspiración a una comprensión global de las realidades y de los problemas. No sin razón ha podido hablar D‘ORS de un «vulgarismo jurídicon que conduce a la disolución de las categorias jurídicas ${ }^{109)}$. Igualmente GROSSO, refiriéndose en concreto al estudio del Derecho Romano y a su enseñanza, previene contra el peligro de aproximarse a él desde puntos de vista de utilidad práctica inmediata(110). Por supuesto, tan poco seria aceptable una pretendida actitud científica que degenerara en abstracciones desvinculadas de la realidad o en la mera erudición.

Las reservas que deben hacerse a esta mentalidad pragmática, no impiden en absoluto preguntarse por la utilidad del estudio actual del 
Derecho Romano y por las razones que han hecho y hacen de él un modelo válido para otras sociedades y pueblos. Esta indagación conduce últimamente al reconocimiento de la perfección intrínseca del Derecho Romano, elaborado a través de un proceso secular de experiencia jurídico-social, con un método ejemplar y perfectamente adaptado a su período histórico. Por supuesto, no se trata de hacer una Historia del Derecho Romano ad usum de los juristas modernos, sino de saber encontrar una síntesis histórico-jurídica que no pierda de vista el carácter del objeto de que se hace la historia, que es un Derecho y que debe ser estudiado por hombres del Derecho(111).

En nuestra actual situación histórica, y teniendo en cuenta la compleja problemática jurídica y política que están viviendo nuestras sociedades occidentales, es posible ilustrar las razones de la ejemplaridad y actualidad del Derecho Romano, recordando algunos rasgos fundamentales o contenidos esenciales que le son propios. Entre ellos destacaremos únicamente tres: cómo se plantea el problema de la justicia en el ius romanum y cuál es su dimensión humanista; la no estatalidad del Derecho, como correctivo a las tendencias iuspositivistas imperantes y, por último, la certeza del Derecho, en cuanto alternativa a la mera legalidad formal.

\section{B.-El lus romanum y el problema de la justicia}

Aunque parece evidente que la civilización europea ha encontrado en el sistema de las leyes romanas los principios de su propia vida, debe añadirse que también se encuentran actualizadas en el Derecho romano-y gracias a él-otras muchas exigencias y aspiraciones que son propias de ella. Ante todo, una determinada idea de la justicia, concebida como el fin supremo al que tiende el derecho y que no se deriva de abstracciones arbitrarias sino del sentimiento vivo de la conciencia común. Justicia, pues, entendida como una conquista permanente, como un esfuerzo colectivo para adaptar el derecho a las exigencias siempre nuevas de la vida, presidido por una rigurosa conciencia ética, tal como se expresa de forma explícita en la celebérrima definición de CELSO (ius est ars boni et aequi).

En este sentido, y aun reconociendo el fondo de verdad que se contiene en su observación, es importante hacer algunas precisiones a la afir- 
mación de ORTEGA Y GASSET según la cual el hecho de que el pueblo romano hiciera del derecho su pasión primordial no puede ser entendido por la mentalidad moderna que "cree torpemente que el derecho es derecho porque es justo, mientras que el romano castizo pensaba, inversamente, que lo justo es justo porque es derechow(112).

En efecto, y como oportunamente subraya BIONDI(113), la definición de CELSO pone de relieve la función y la orientación fundamental del ius, que debe inspirarse siempre en el bonum et aequum y tender a realizarlos en la práctica cotidiana. De hecho, toda la evolución jurídica romana demuestra un esfuerzo constante por parte de la Jurisprudencia y de los diferentes órganos legislativos para adecuar el derecho a la aequitas, tal como ésta es sentida e interpretada en los distintos períodos históricos.

Por otra parte, aunque el derecho no impone un comportamiento conforme a la moral, no prescinde en modo alguno de ella. Al contrario, los romanos no dudan en asumir, dentro del ámbito del derecho, como elementos cardinales de su ordenamiento más avanzado, algunos conceptos puramente éticos, profundamente arraigados en ellos hasta el punto de constituir "saldissima norma dell,operare praticow(114). Esto debe tenerse en cuenta sobre todo con referencia al concepto romano de la fides que es, sin duda, la regla más alta de conducta moral del ciudadano romano. $\mathrm{Cl}-$ CERON llega a afirmar incluso que es el fundamento mismo de la justicia (fundamentum... est iustitiae fides).

Idénticas consideraciones podrían hacerse a propósito de la aequitas, que preside el desarrollo del derecho desde la República y que se orienta a garantizar la igualdad, que inspira el ius honorarium, que constituye el fundamento del ius naturale y funda la inderogabilidad de los preceptos morales(115). No sin razón observa J. IGLESIAS que "la aequitas impregnada de sentido moral-social, domina el entero territorio-no rigurosamente acotado-del iusw(116).

Aequitas y fides, que penetran en el ámbito del ius civile, terminan animando al sistema romano en su totalidad y constituyen una de las razones del triunfo sobre el formalismo. Posteriormente y, por influencia del Cristianismo, la concepción clásica de la justicia atenúa su severidad en el sentido de una mayor humanidad, tal como aparece en el Corpus luris, 
donde el ideal cristiano de la justicia está presente en todo el ordenamiento jurídico, introduciendo en él un nuevo espíritu de solidaridad social que era desconocido anteriormente. No es improbable que la nueva justicia cristiana sea menos idónea que la clásica para el gobierno de los hombres, pero es indudable que aquel ideal se enriqueció de un contenido ético incomparablemente más alto(117).

Por otra parte, hay que observar que este espiritu del Derecho romano no se encuentra sólo en los textos jurídicos, sino que late también en los textos literarios y "en la imagen larga de la Roma toda". J. IGLESIAS señala acertadamente que uel Derecho tiene su basamento en unos principia. Tales principios enraizados, a su vez, en un mundo de creencias, de sentimientos, impulsos, necesidades políticas, económicas y de otra varia suerte, no se vierten del todo, con precisiones contables o mensurables, en lo jurídico positivo. Sin embargo, en el todo que es la vida colectiva actúan, difusa e impalpablemente.... ${ }^{(118)}$ :

Estudiando los aspectos más universales del pensamiento romano, BIONDI llama la atención sobre el hecho de que el hombre aparece en el centro del ordenamiento jurídico y recuerda una afirmación recogida en el Digesto: totum ius hominum causa constitutum est(119). Los libros de Institutiones de los juristas romanos se abren siempre con el tratado del ius quod ad personas pertinet. Se habla de homo y de persona, más bien que de civis. Esto tiene importancia y significación en cuanto que el ordenamiento jurídico está constituido para la utilitas omnium, que es invocada frecuentemente para justificar institutos y decisiones.

Ahora bien, si todo el Derecho está constituido hominum causa y para su utilidad, aparece conforme a la esencia y función del Derecho el que esté conforme a la humanitas. Esta palabra que, desde su nacimiento en Roma en el siglo II a. C., fue asumiendo una gran variedad de significados y matices (120), ha terminado siendo, como observa S. RICCOBONO, una síntesis abreviada de los ideales morales e intelectuales que han ejercido un influjo más profundo en el progreso de la civilización(121).

En el ámbito del derecho, el término humanitas sólo fue acogido por los juristas, junto con humanus y sus derivados, después de la época clási$\mathrm{ca}$, viniendo a significar lo mismo que aequitas y siendo idéntica su fun- 
ción práctica(122). La humanitas pasa a ser entonces el nombre que toma la aequitas como expresión de benignitas, de pietas, de charitas. Por influencia del cristianismo, y a fin de eliminar la equivocidad que tenía hasta entonces la palabra humanitas, Justiniano terminaría hablando de una «nova humanitatis ration(123), subrayando así la aportación cristiana a la configuración de un orden nuevo de relaciones humanas(124).

La humanitas, que está muy directamente relacionada con el ius y la aequitas ${ }^{125)}$, aparte de su sentido específico (como benevolencia, solidaridad, o clemencia), es una noción universal, como pueden serlo "civilización» o «conciencia social»(126).

Aunque debe admitirse una cierta continuidad entre la humanitas romana y la cristiana, existen profundas diferencias que no pueden explicarse como un mero proceso de desarrollo o perfeccionamiento. En el cristianismo, la humanitas no es sólo una especulación filosófica; es un precepto religioso. Además, el concepto de hombre y persona se transforma radicalmente(127) y, por tanto, también su autoconciencia y el sistema de relaciones con los demás, en la sociedad y en el Estado. La charitas cristiana no se identifica ya sin más con aquella "charitas generis humani" que habian exaltado los estoicos.

La invocación a la humanitas en la legislación postclásica está en estrecha conexión con la penetración del cristianismo en el Imperio. Cuando CONSTANTINO, como harán otros emperadores posteriores, declara que las leyes pretenden humano generi prospicere(128), no quiere significar solamente que deben encaminarse a satisfacer las necesidades sociales; se está actuando, más bien, la consideración de los nuevos fundamentos que sustentan las relaciones humanas. En este sentido es evidente la conexión profunda que se establece entre la humanitas y la función específica nueva que corresponde a la aequitas en el proceso de humanización del derecho.

Después de un estudio detenido de los textos legislativos postclásicos, BIONDI concluye con la afirmación de que la humanitas-que era ya uno de los motivos que tenían presente el legislador y la jurisprudencia de la época clásica-constituye el motivo general y prevalente(129), llegando a 
ser incluso superior a la misma justicia. La Sirmondina 13 recoge un pasaje de los emperadores HONORIO y TEODOSIO en el que explícitamente se declara: "convenit nostris praescita temporibus, ut iustitiam inflectat humanitasw(130).

Por otra parte, es indudable que de la humanitas se derivan los derechos de la personalidad, respecto de los cuales cada sociedad y cada época tienen una particular sensibilidad. Entre ellos hay que citar el principio de la integridad física y moral del hombre, la libertad, entendida como naturalis facultas que preexiste al ordenamiento jurídico, etc.

\section{C.-La no estatalidad del Derecho: antítesis ius-lex}

Una de las ideas fundamentales que debe destacarse al abordar el estudio del Derecho Romano, y que representa, sin duda, un evidente valor de ejemplaridad para cualquier tiempo, es la no estatalidad del ius, la desvinculación existente entre Estado y Derecho privado; en otras palabras, la antítesis del positivismo jurídico moderno. Aquí radica, por otra parte, la clave de la dístinción de Roma respecto de los demás pueblos occidentales(131). En efecto, en Roma el Derecho privado procede de la actividad de los iurisprudentes y este fenómeno constituye un hecho de tal importancia que toda la Historia del Derecho Romano podría reducirse a la historia del dualismo o antítesis iux-lex.

El ius era para los romanos esencialmente interpretatio: la ley viene a colocarse en los márgenes de ésta e incluso cuando se desarrolla de forma más vigorosa deja sobrevivir la interpretatio, que siempre es considerada como el ius civile por antonomasia. El dualismo entre interpretatio y legislación no se reduce a la distinción entre derecho extraestatal y derecho estatal, como podría parecer a primera vista; ni tampoco hablar de progresiva estatalización del Derecho es afirmar la íntima esencia del fenómeno, ya que un elemento de estatalidad existe siempre en la interpretatio, desde el momento en que los resultados de ella son asumidos por el órgano jurisdiccional del Estado. La antítesis se da más bien entre lo que es verdaderamente un desarrollo lógico y orgánico y lo que es únicamente imposición del Estado.

Bajo el signo de este dualismo se inicia la historia del Derecho Romano y quizá hasta JUSTINIANO no se da verdadera fusión del ius y las leges en uni- 
dad legislativa de origen estatal. La puesta en marcha hacia la unificación formal se verifica con el advenimiento del poder imperial, es decir, cuando la constitutio principis llega a ser la fuente única de derecho, a la cual se da el nombre solemne de lex, excluyendo la posiblidad de que otras fuentes puedan crearlo. La unificación puede decirse que se ha realizado formalmente por el hecho mismo de que cada una de las constituciones de JUSTINIANO han dado valor de ley a tódo el complejo heterogéneo de material jurídico recibido a través de la secular tradición de Roma. Ahora el derecho es uno sólo y deriva únicamente de la lex. Todas las fuentes precedentes pierden eficacia a partir de las leyes promulgadas por JUSTINIANO. La referencia a ellas está inspirada no sólo en un sentimiento de reverencia hacia el mundo antiguo, sino también en el deseo de hacer inteligible todo el complejo legislativo.

Esta fusión que venia preparándose desde el Principado, a causa del creciente predominio de las leges, se debe también al encauzamiento oficial de la actividad de los prudentes. A propósito de éstos, puede decirse que con su labor de interpretatio fueron moldeando el ius a las nuevas exigencias, de modo que puede decirse con BETT/132) que la Jurisprudencia fue en realidad fuente del Derecho. GROSSO coincide con esta afirmación subrayando cómo la interpretatio prudentium, heredera de la más antigua jurisprudencia pontifical, es uno de los elementos fundamentales del desarrollo del ius civile romano(133). La gran contribución de la Jurisprudencia a la creación y determinación de este ius civile romano tuvo lugar antes e independientemente del ius respondendi. Hasta tal punto es importante esta obra que POMPONIO llega a afirmar que el ius civile "in sola prudentium interpretatione consistit, ${ }^{134)}$. No se trata únicamente de una interpretatio intelectual, sino que es también evolutiva; no es una actitud teórica sino práctica. Tarea suya es, sobre todo, el fijar en una fórmula precisa la tradición, entendida como algo vivo, no como realidad inmóvil.

Desde los primeros tiempos de Roma hasta finales de la República, el ius venía a ser el conjunto de normas según las cuales se regían los conflictos de intereses de la sociedad romana. La lex era la norma establecida por los comitia que, muy de tarde en tarde, intervenian en la vida civil del civis romanus(135).

Estudiando la relación entre ius y lex, MITTEIS llega a la conclusión de que en todo tiempo, el derecho creado por la ley ha podido ser cualificado 
como ius(136). Si la lex ha sido algunas veces opuesta al ius, esto se debió a que se quería designar el derecho expresamente formulado, en oposición al que no lo estaba: pero ha sido considerada como una parte del ius, así como, más raramente, el ius ha podido ser cualificado como lex. KASER piensa que no hubo, en el origen, ninguna relación entre lex y ius. Mientras que ius, según él, no habría designado más que una actitud, una línea de conducta reconocida, permitida, tenida por justa a causa de una decisión judicial en cada caso concreto, definida sin apoyarse sobre una norma, la lex sería una prescripción o decisión limitada a un caso concreto también, de modo que ambos conceptos parecen haber sido fundamentalmente diferentes. Sin embargo, se habrian aproximado al estar aplicados a normas generales, conduciendo así a reconocer la equivalencia de los principios establecidos en el juicio y en la ley, y por tanto, a entender como ius el derecho creado por la ley. PAOLI insiste también en que deben desaparecer las fronteras entre los dos dominios, apoyándose en la existencia, sólidamente atestiguada en el curso de la época intermedia entre los orígenes y la época postclásica, de un concepto en que se han encontrado perfectamente conciliados el ius y la lex: este concepto es el de ius legitimum(137).

La vinculación entre ius y mores maiorum, parece innegable(138). El ius-conjunto de imperativos de conducta-se formó progresivamente, por vía de costumbre o convenciones implícitas entre los asociados y, de modo más preciso, por costumbres dotadas de particular autoridad, que serían los mores maiorum.

Al estudiar el papel de las leges frente al ius, observamos que en las leges se dan sucesivas imposiciones de la clase plebeya en sus luchas frente al patriciado. Prueba decisiva en este sentido sería el hecho de que las leges más conocidas han sido votadas por las asambleas de la plebe; son técnicamente plebiscitos. Además, comenzando por la misma tradición respecto a las XII Tablas, la finalidad de la legislación romana parece ser la seguridad jurídico-social de las clases inferiores(139).

Si estudiamos, por otra parte, la interpretatio prudentium en su relación con la legislación, vemos en esta última el medio de superar los momentos de impotencia creadora de la interpretatio(140). En efecto, en un primer momento el derecho es sólo interpretatio, una formación lógica al 
margen de toda autoridad. A medida que aparece insuficiente, interviene la ley que, siendo expresión de autoridad, completa la interpretatio llegando hasta donde ésta no puede llegar. Cuando la interpretatio carece ya de virtud creadora suficiente para colocarse al ritmo del progreso social, se hace necesaria la corriente innovadora de la legislación. Es indudable que, en algunos casos, ésta habrá sido la razón de la legislación, pero, normalmente el órgano verdaderamente renovador ha sido el pretor(141). Unicamente en graves casos de crisis colectivas se presentaría como necesidad el acudir a la lex. Por otra parte, la virtud creadọra de la interpretatio ha constituido lo que en la técnica jurídica actual se denomina puente del derecho(142).

Más que la legislación ha sido el pretor el que realizó la acomodación del ordenamiento jurídico al ritmo de la sociedad. En este sentido pudiera decirse que el pretor es un órgano casi legislativo, tal es su arbitrio jurisdiccional. El edicto pretorio, como ya insinúa CICERON, es la fuente más importante de la disciplina iuris. La separación tradicional en la romanistica entre ius civile y el edictum ha impedido valorar a éste como la máxima fuente del ius. El edictum es el documento que más nos acerca a la realidad de la vida jurídica romana(143).

\section{D.-Legalidad formal y certeza del Derecho}

A fin de entender cómo se plantea en Roma el problema de la certeza y seguridad jurídicas, es preciso hacer referencia, una vez más, a la íntima conexión existente entre Derecho y Política en Roma. En efecto, la política romana, en su multiplicidad de manifestaciones, está orientada no por efímeras ideologías sino por un sentimiento profundo de la supremacia y perennidad del Populus Romanus, concebido como una fuerte y solida organización jurídica(144). La Res Publica, desde el punto de vista político, expresa la idea de comunidad política, siendo su vínculo más fuerte y perenne la lex publica(145). En este sentido, la lex ues un concepto eminentemente político(146).

Aunque pueda parecer una paradoja-dice BIONDI-es indudable que Roma ha tenido un ordenamiento fuerte y preciso pero no una constitución, entendida como una enunciación abstracta de principios, de órga- 
nos y funciones del Estado. Réino, República, Principado son denominaciones modernas aproximativas, con las cuales indicamos diversos períodos históricos, pero los romanos no tienen ni siquiera un nombre para describir su propio régimen político. A través de las diferentes crisis, la política romana busca siempre mantener sólido el ordenamiento del Estado. A través de la organización jurídica, los romanos, más que teoriz̧ar, han demostrado con la praxis misma de qué modo puede conciliarse el principio de autoridad con el de libertad, la fuerza y la justicia(147).

Al abordar el problema de la certeza del derecho en Roma, SCHULZ distingue dos significados en la "Rechtssicherheit»: a) la certeza de que, en la lucha contra el mal, prevalecerá el derecho; b) la certeza del derecho existente, la posibilidad de reconocer con seguridad el ordenamiento jurídico y de prever. los efectos jurídicos que van a surgir de una determinada situación de hecho(148). La seguridad o certeza del Derecho, entendida en el primer sentido, depende esencialmente de la garantía que el Estado ofrece a la tutela jurisdiccional. Después de examinar una serie de datos, el autor piensa que en la época clásica y republicana la tutela jurídica por parte del Estado estaba suficientemente garantizada, es decir, que en este sentido existía la certeza del Derecho. Pero, entendida en la segunda forma señalada, cree que no puede hablarse de la seguridad acerca de la norma jurídica, e insiste en que uno de los caracteres del Derecho Romano es justamente la poca importancia que en él se otorga a esta certeza. Por una parte, no es muy clara la existencia y el contenido de las normas jurídicas (es conocida la poca propensión de los romanos a la promulgación estatal de las normas); por otro lado, incluso alli donde existe un derecho fijado por el Estado, tampoco es fácil el formarse una certeza. Si en la época republicana y en el período clásico esta falta de seguridad podia soportarse e incluso no era sentida como un defecto, esto se explica por el hecho de que existía una doctrina jurídica floreciente, en la cual los cives tenían la máxima confianza. En fin, SCHULZ señala como una causa de la falta de certeza del derecho, el poder discrecional de los órganos del Estado, en especial, de los magistrados iusdicentes, a los cuales se otorgaba una amplia esfera de acción.

A la vista de todas estas dificultades creo, con MASCHI, que la certeza del Derecho no debe hacerse consistir en la certeza formal, exterior, entendida 
como simple legalidad, sino en la certeza sustancial, esto es, certeza de los principios fundamentales de los ordenamientos, en la certeza como objetividad(149). No es exacto, pues, afirmar que no han alcanzado la certeza del Derecho aquellos ordenamientos que (como los ordenamientos jurídicos romanos), no se han preocupado de formular unas normas exhaustivas encaminadas a prever todos los casos posibles. De hecho, no sólo la ley en sí misma, sino también el modo según el cual la ley opera modernamente, contradice a la certeza del Derecho. Hay que hacer referencia, en este sentido, al hecho de que la certeza disminuye precisamente en cuanto que, en nuestro tiempo, hemos llegado, como escribe CARNELUTTI, a una «hipertrofia de la leys(150).

Desde otra perspectiva, U. ALVAREZ ha observado que el jurista actual vive dentro de un ordenamiento jurídico cerrado, emanado de una sociedad política estructurada sobre el esquema de una constitución estatal orgánica en la que se destaca el predominio decisivo de la ley. Por esto se siente constreñido a negar a la jurisprudencia, entendida como doctrina judicial, el valor de fuente directa del derecho. El jurista romano, en cambio, fue la pieza clave creadora del proceso formativo del Derecho en Roma; por eso, el romanista actual, propende a enfrentarse con el actual predominio de la ley y considera que ésta es un obstáculo en la formación espontánea del Derecho(151).

Los romanos no reducían el problema de la certeza a un problema de legislación. Para ellos, la ley tenía un ámbito de operatividad muy preciso y limitado. Teniendo en cuenta la poca relevancia de la legislación en el mundo romano clásico, es muy significativo el hecho de que la obra legislativa de AUGUSTO, concretada en las leges, senadoconsultos o edictos, puede calcularse en unas cuatro leyes por año, unas doscientas en cincuenta años de gobierno. Este número, que a nosotros puede parecernos ridículo, debió causar en sus contemporáneos una impresión muy distinta, dado que jamás en Roma se había visto una actividad legislativa tan vasta e importante(152). Por otra parte MASCHk153) llama la atención sobre el hecho de que el paso de la constitución republicana a la del Principado no tuvo lugar a través de la ley, ya que ninguna ley abole el antiguo régimen y ninguna instaura el nuevo. En este sentido es indudable que el "popolo del diritto non è il popolo de la legges(154). En el derecho privado, frente a los mores maiorum y la interpretatio de la jurisprudencia (la parte más amplia y relevante del ius civile) la legislación interviene 
para actuar disposiciones particulares, con el fin de evitar abusos en las aplicaciones del derecho tradicional. Todo esto no significa que exista una carencia de consideración hacia la ley, que es considerada como altísima fuente del derecho; al contrario, se tiene la conciencia de que la legislación debe intervenir-y de hecho interviene-sólo cuando es indispensable. Además a la formación de la ley concurre una pluralidad de organos que representan a la civitas en su totalidad: el magistrado, el pueblo, el senado; la lex rogata es entendida como lex publica por la intervención determinante del pueblo, reunidos los comicios, y como acto bilateral intercurrente entre la propuesta del magistrado y la aceptación del pueblo. En suma, en el Derecho romano clásico no tiene razón de ser la objeción que se hace a propósito de la certeza del Derecho basándose en la amplitud del poder discrecional del magistrado o en la poca importancia que se da a la promulgación estatal de las normas.

El problema de la certeza se planteó en el mundo romano y fue resuelto desde otra perspectiva. Que haya sido sentido realmente, nos consta a través de términos explícitos. Así, en la época de TRAJANO y ADRIANO, NERACIO expresa la exigencia de certeza en términos que la hacen prevalecer sobre el deseo mismo de indagar las razones del ordenamiento jurídico: "ratione. eorum quae constituuntur inquiri non oportet: alioquin multa ex his, quae certa sunt subvertuntury(155). A proposito de este texto y de otro de JULIANO(156), hay que observar, frente a SCHULZ y LUBTOW, que no debe pensarse que en ellos se excluya una crítica del ordenamiento: a primera vista habría que convenir en excluirla, pero observando con una panorámica más amplia la evolución del Derecho romano, habría que rectificar y sostener, por el contrario, que la función pretoria, la Jurisprudencia y la cognitio extra ordinem, suponen una amplísima crítica del ordenamiento(157).

En cuanto a la forma como resolvieron el problema de la certeza, creo que es exacta la explicación de MASCHI, el cual subraya cómo los romanos no se preocupan de la certeza aparente o formal de la ley, sino que todo el desarrollo del Derecho clásico está orientado a conseguir la certeza sustancia(158). Esta certeza viene dada, en primer lugar, por un criterio general que sirve como norma para el comportamiento de las partes y para la valoración del magistrado y del juez. Los romanos lo expresan con el binomio bonum et aequum. Gradualmente va desarrollándose una constante adaptación 
a este bonum et aequum, a través de las actiones in bonum et aequum conceptae y los iudicia bonae fidei, hasta que la noción de bonum et aequum termina siendo - junto con la bona fides-expresión de una norma de conducta que se requiere en los más varios negocios; un sucesivo proceso de abstracción, obra de la Jurisprudencia clásica más evolucionada, llega a definir todo el derecho sobre la base del bonum et aequum, o a valorar el derecho, desde un punto de vista realista, como actuación del aequum et bonum.

La certeza del Derecho viene dada, en segundo lugar, por el mismo poder discrecional del magistrado, en la iurisdictio del proceso formulario. En efecto, el principio supremo a que hemos aludido quedaría reducido a pura especulación si no existiera un órgano capaz de asegurar su actuación concreta. Este órgano es el poder del magistrado iusdicens. Si este poder de los pretores representa un amplissimun ius según la expresión de GAYO(159), no significa un poder arbitrario ni es fuente de inseguridad: en primer lugar, porque dentro de la masa del derecho consuetudinario la tradición hace que vayan surgiendo iura, los cuales, como afirma CICERON, han venido a ser certa propter vetustatem(160); además, algunas leges fundamentales constituyen puntos ciertos de orientación tanto para el magistrado como para el indivíduo en particular. Por último, el Edictum del Pretor no hace que surjan derechos subjetivos en los indivíduos, aunque sí una expectativa: siendo el magistrado soberano en la aplicación del derecho, puede ir más allá del Edictum, y conceder, mediante decreta soluciones para casos particulares no contemplados en él. Sin embargo, como subraya el mismo MASCH(161), es obvio que el magistrado no publica el Edictum para no aplicarlo después, que la fides (exigida por el magistrado a los particulares) constituye un vínculo entre el magistrado y las partes para la observancia del Edictum, y que la intercessio representa una sanción a la violación de la fides por parte del magistrado y, por tanto, una garantía contra todo posible abuso. En suma, el mecanismo que opera a través del Edictum y del poder discrecional, es una conciliación de cuanto parece inconciliable, es decir, la estabilidad propia de las normas positivas ya constituidas y la mutabilidad propia del poder discrecional, de modo que todos los elementos concuren a hacer posible una certeza sustancial: predeterminación y variabilidad, la conciliación en el máximo instrumento de la administración de la justicia de estos dos elementos, "representa la obra maestra de la sabiduría jurídica romanas(162). 


\section{NOTAS:}

(1) A. LATORRE, Valor actual del Derecho Romano, Barcelona, 1977.

(2) J. IGLESIAS, Espiritu del Derecho Romano, Madrid, 1980.

(3) A. D'ORS, lus Europeaum, en "L'Europa e il Diritto romano", I. pp. 47-68.

(4) B. BIONDI, Obietto e metodi della scienza giuridica romana, en «Scritti Giuridici», I, p. 101.

(5) B. BIONDI, Obietto e metodi della scienza giuridica romana, en «Scritti Giuridici», I, p. 102 y ss.

(6) Cf. E. DI ROBILANT, La configurazione delle teorie nella sciencia giuridica, R. I. F. D., 53 (1976), p. 492 y ss.

(7) E. DI ROBILANT, art. cit., p. 493; reconstruir el carácter propio del «discurso» de la ciencia jurídica apoyándose en este tipo de representación significa, por tanto, tomar como emblemática y exclusiva una abstracción o idealización.

(8) G. GROSSO, Premesse generali al corso di Diritto Romano, Torino, 1960, p. 43.

(9) Cf. E. BETTI, Teoria generale del negozio giuridico, cit., p. IX, alude a la estrecha conexión que existe entre el trabajo de sistematización y la realidad empírica, al observar que la. teoría general del negocio que él ha elaborado intenta demostrar la capacidad de renovación frente a los nuevos problemas y exigencias sociales.

(10) E. DI ROBILANT, art. cit., p. 495.

(11) G. GROSSO, Premesse generali..., ed. cit., p. 55. Cf. J. IGLESIAS, Espíritu del Derecho Romano, Madrid, 1980, p. 87 ss., donde el autor señala como uno de los rasgos del ius romanum la "concreción", el hecho de que las instituciones juridicas nacen en respuesta a necesidades prácticas sentidas en cada momento.

(12) G. GROSSO, Premesse generali..., ed. cit., p. 55.

(13) Cf. A. LATORRE, Valor actual del Derecho Romano, Barceiona, 1977, p. 26. Para una mayor profundización cf. RICCOBONO, La giurisprudenza classica come fattore di evoluzione nel diritto romano, en "Scritti Ferrini”, p. 42 y ss.; LA PIRA, La genesi del sistema nella giurisprudenza romana: Problemi generali, en "Studi Virgilin, Siena, 1935, p. 158 y ss, ${ }_{;}$U. ALVAREZ, La jurisprudencia romana en la hora presente, Madrid, 1966; CANNATA, La Giurisprudenza romana, Torino, 1976; O. ROBLEDA, Introduzione allo studio del diritto privato romano, Roma, 1979, p. 100 y ss. (el autor estudia en la p. 105 y ss. la tarea específica de los iusrisprudentes, su labor creadora de derecho, sus técnicas, la naturaleza de la interpretación jurídica, etc., precisando más adelante cuáles entre ellos pueden y deben considerarse como verdaderos creadores de derecho); interesa también la reciente aportación de BRETONE, Tecniche e ideologie dei giuristi romani, Napoli, 1971.

(14) P. DE FRANCISCI, Per il centenario del Digesto, en "XIV Centenario della Codificazione Giustinianeas, I-2 (1933), p. 20.

(15) M. KASER, En torno al método de los juristas romanos, Valladolid, 1964, p 15.

(16) B. BIONDI, Obbietto e metodi della scienza giuridica romana, en "Scritti giuridici», I, p. 104.

(17) CICERON, De officiis, I, 43, 153.

(18) M. KASER, op. cit., p. 17 y ss. 
(19) A. CARCATERRA, Le definizioni dei giuristi romani, Nápoles, 1966, p. 115.

(20) A. CARCATERRA, Le definizioni dei giuristi romani, cit., p. 214 ss. (con abundante bibliografía y descendiendo a ejemplos prácticos que ilustran su posición). Al final de su libro hace notar que todavía hoy la ciencia del derecho tiene que reconocer a los romanos muchas definiciones que usa.

(21) F. SCHULZ, I principi del diritto romano, Florencia, 1946, p. 93 y ss.

(22) A. CARCATERRA, Le definizioni..., ed. cit., p. 215 y ss.

(23) CICERON, De officiis, I, 72.

(24) M. KASER, En torno al método..., ed. cit., p. 37.

(25) A. GUARINO, Diritto privato romano, ed. cit., p. 82.

(26) A. GUARINO, Op. cit., pp. 82-83.

(27) B. BIONDI, Interpretatio iurisprudentium e legis/azione, en «Scritti, Giuridici», I, p. 323; ROTONDI, Osservazioni sulla legislazione comiziale romana di diritto privato, en «Scritti» I, p. 1 y ss.; Leges Publicae populi romani, Milán, 1912.

(28) Cf. el volumen colectivo La Filosofia Greca e il Diritto Romano, Accademia dei Lincei, Roma, 1976-1977.

(29) M. KASER, En torno al método..., ed. cit., p. 40.

(30) G. LA PIRA, La genesi del sistema della giurisprudenza romana. L'arte sistematrice, BIDR, 42 (1934), p. 331 y ss.

(31) Una bibliografía acerca de los principales representantes de la Jurisprudencia Romana, puede verse en A. GUARINO, L'esegesi delle fonti del Diritto Romano, I, Nápoles, 1968, pp. 104-105; a propósito de M. SCAEVOLA, cf. GROSSO, P. M. SCAEVOLA, tra il Diritto e la politica, en A. G., 175 (1968),p. 204 ss.; sobre POMPONIO, cf. M. BRETONE, Motivi ideologici dell, Enchiridion di Pomponio, Labeo, 11 (1965), p. 7 ss.

(32) F. SCHULZ, I principii..., ed. cit., p. 93 y ss.

(33) F. SCHULZ, I principii..., ed. cit., p. 94.

(34) W. KUNKEL, Herkunft und soziale Stellung der römischen Juristen, Colonia, 1967.

(35) Cf., entre otros, B. BIONDI, La terminologia romana come prima dommatica giuridica, en «Scritti Giuridici», I, p. 181 ss.; A. CARCATERRA, Struttura del linguaggio iurido-precettivo romano, Bari, 1968.

(36) C. A. MASCHI, // Diritto Romano, I, (La Prospettiva storica della Giurisprudenza Classica), Milán, 1966.

(37) C. A. MASCHI, // Diritto Romano, I, ed. cit., p. 14.

(38) D. 1, 2, 2 Pr.

(39) A propósito de GAYO, por ejemplo, hay que observar que enuncia igualmente, en términos generales, y del mismo modo que POMPONIO, un programa historiográfico. En D. 1,2, 1 y refiriéndose a la Ley de las XII Tablas, leemos: «facturus legum vetustarum interpretationem necessario prius ab urbiis initiis repetendum existimavit) (cf. el comentario en MASCHI, op. cit., p. 133 y ss.

(40) P. FUENTESECA, Historia y Dogmática en la jurisprudencia Europea, Rev. Dcho. Notarial, 11 (1956, p. 183 y ss.

(41) P. FUENTESECA, ibidem, p. 202. 
(42) R. ORESTANO, Introduzione allo studio storico del diritto romano, Turín, 1953, p. 218 y ss.; donde estudia la Escuela Histórica, el método sistemático y la Pandectística.

(43) M. ROSSI, Storia e Storicismo nella Filosofia Contemporanea, Milán, 1960, p. 94 y ss.

(44) E. PARESCE, Art. "Scuola Storica del Diritto", Noviss. Dig. Ital., XVII, p. 826.

97.

(46) J. A. ESCUDERO, Historia del Derecho: Historiografia y Problemas, Madrid, 1973, p.

(46) J. A. ESCUDERO, op. cit., p. 97.

(47) E. BETTI, Isti. di diritto romano, Padua, 1942, vol. 1. ${ }^{\circ}$.

(48) R. ORESTANO, Introduzione allo studio storico del diritto romano, Torino, 1953, p. 61 ss.

(49) Ibidem. p. 66; sf. también GIANNINI, Sociologia e studi di diritto contemporaneo, en "Jus", 8 (1957); el mismo ORESTANO ha expuesto ampliamente la dirección sociológica de los estudios romanísticos en su art. Sociologia e studio storico del diritto, en «Jus", 8 (1957), p. 200 ss.

(50) P. DE FRANCISCI, I presupposti teoretici e il metodo nella storia del diritto, Riv. I. de Sociologia, 20 (1916); ID. Dommatica e storia nell, educazione giuridica, R. I. F. D., 361923 ).

(51) B. PARADISI, Gli studi di storia del diritto italiano..., en "Studi Senesin, 60 (1947), p. 68.

(52) Cf., por ejemplo, CARRELLI, A proposito di crisis di diritto romano, SDHI, 9 (1943), p. 7 y ss.

(53) Ibidem, p. 7.

(54) R. ORESTANO, Introduzione..., p. 68.

(55) El propio ORESTANO ha advertido que el elemento constitutivo de la experiencia jurídica es la misma actividad humana; que da vida a la experiencia; esto es, todo el mundo de la "acción" y las complejas implicaciones de ésta es lo que viene a ser tomado como objeto de estudio. En este sentido, nada de cuanto pueda conducirnos a esa experiencia puede ser considerado como irrelevante.

(56) R. ORESTANO, introduzione,,, p. 69.

(57) P. DE FRANCISCI, Punti de orientamento per lo studio del Diritto, RISG, 3 (1949), p. 69 y ss. (cf. especialmente p. 73). Para él, el ordenamiento jurídico, desde un punto de vista lógico, no es más que una especie de un género más vasto que podemos llamar "ordenamiento social", dentro del cual vive y se desarrolla, al lado de otros (ib., p. 73).

(58) A. MOMIGLIANO, Rinnovamento della storia dei diritti antichi (Le consequenze del),en "La Storia del Diritto nel quadro delle scienze storiche», Firenze, 1976, p. 21 ss.

(59) Ibidem, p. 23.

(60) A. GARCIA-GALLO, El origen y la evolución del Derecho, I, Madrid, 1973, pp. 20-21; cf. G. NOCERA, Un,esperienza storicistica sul fundamento del potere politico, R.I.F.D., 27 (1950), p. 569 .

(61) A. GUARINO, L,Esegesi delle fonti del Diritto Romano, I, Napoli, 1968, p. 26.

(62) R. ORESTANO, Introduzione..., ed. cit., p. 208 y ss.

(63) R. ORESTANO, Introduzione..., ed. cit., p. 219 y ss.

(64) Ibidem, p. 221 y ss.

(65) Cf. J. IGLESIAS, Presente y futuro del Derecho Romano, en «Studi BISCARDI", I, 1981. 
(66) R. BADENES GASSET, Metodología del Derecho, Barcelona, 1959, p. 403. A principios del siglo el tema fue abordado por WENGER refiriéndose explícitamente a la función del Derecho Romano en la Universidad (Die Stellung des öffentlichen römischen Rechts im Universitätsunterrichte, Viena, 1907).

(67) J. ORTEGA Y GASSET, Función de la Universidad, O. C., IV, 1951, p. 313 y ss.

(68) P. LAIN ENTRALGO, La Universidad en la vida española, Madrid, 1958; esta temática se desarrolla en otras obras similares como J. MARIAS, La Universidad, realidad problemática, Santiago de Chile, 1953; J. L. ARANGUREN, El futuro de la Universidad, Madrid, 1953; A. TOVAR, Universidad y educación de masas, Barcelona, 1968; MEILAN GIL, Los planes universitarios de enseñanza en la España contemporánea, Madrid, 1970; un estudio histórico que interesa a nuestro propósito es el de ALVAREZ DE MORALES, La Ilustración y la reforma de la Universidad en el s. XVIII, Madrid, 1971.

(69) J. GUASP, La cultura del jurista, R.D.P., 4 (1957), especialmente p. 480-482.

(70) ALVAREZ TURIENZO, La lucha por el derecho y la autorrealización del hombre, en "Miscelánea en honor de Juan Becerril y Antón Miralles", Madrid, 1974, p. 46.

(71) J. IGLESIAS, Presente y futuro del Derecho Romano, art. cit., p. 1.

(72) A. LATORRE, Valor actual del Derecho Romano, op. cit., p. 25 ss.

(73) P. KOSCHAKER, Europa y el Derecho Romano, Madrid, 1955, p. 488 y ss.; más recientemente; entre otros, G. FLORIS MARGADANT, El significado del Derecho Romano dentro de la enseñanza jurídica contemporánea, México, 1960.

(74) P. FUENTESECA, Prólogo a la "Compraventa Civil de Cosa Futura" de A. CALONGE, Salamanca, 1963, p. 8.

(75) A. TORRENT, Introducción metodológica al estudio del Derecho Romano, Oviedo, 1974, p. 143.

(76) B. PARADISI, // problema della storia del diritto nel contesto della storiografia contemporanea, art. cit., p. XLVI.

(77) J. IGLESIAS, Espíritu del Derecho romano, ed. cit., p. 20. El autor observa que todos estos factores actúan en el área social aunque no es fácil determinar cómo. En este sentido advierte contra el peligro de recurrir a fórmulas expeditivas o generalizaciónes fáciles que pretendiendo esclarecer los hechos confunden y desvian los problemas. En cualquier caso, se trata de una temática en la que las categorías y etiquetas actuales no encuentran una aplicación mecánica y exige un esfuerzo de análisis y acomodación, conscientes de que sólo es posible hoy lo que el propio IGLESIAS Ilama "la difícil faena histórica de la aproximación" (Ib. p. 21).

(78) A. D’ORS, Derecho romano (separata del texto del autor en la N. E. J.7, Barcelona, 1949, especialmente p. 10 y ss.; la expresión a que nos referimos en el texto puede verse en p. 11.

(79) Ibidem, p. 11 y ss.; a propósito del sincronismo a que nos hemos referido anteriormente, el autor señala, entre otros, los hechos siguientes: a) la comisión de los decemviros redactores de la Ley de las XII Tablas no sería sino el reflejo de la situación política inmediatamente posterior a la caída de la dinastía etrusca; b) las tres grandes piezas de la Constitución republicana (Magistraturas, Senado, Pueblo) vienen a representar como los modelos o elementos monárquico, aristocrático y democrático, respectivamente; c) cuando Augusto instaura una nueva forma constitucional, se entra en una nueva era; ahora bien, aunque también en la vida juridica se observan cambios en ese momento, seguimos estando en la época clásica. En los siglos posteriores, la historia política y la historia interna del Derecho coinciden perfectamente. Como 
resultado de la crisis económica, militar y política del s. III, se pierde la unidad espiritual del Imperio y termina haciéndose imposible el mantenimiento de la idea imperial unitaria: uel absolutismo trajo asi el separatismon (lb., p. 13). El autor añade que cuando hablamos hoy de Derecho romano entendemos por este término tan sólo su «derecho civil».

(80) En efecto, las fuentes jurídicas reflejan, más perfectamente que ningún otro documento o monumento histórico, el progreso gradual de la romanitas: sus crisis y sus triunfos, su grandeza y sus debilidades. Este hecho se explica teniendo presente que en Roma la formación del Derecho fue casi exclusivamente consuetudinaria, al mismo tiempo que debe reconocerse la gran influencia que tuvo aquel culto romano por la tradición que domina el desarrollo jurídico en cada una de sus fases. El Derecho, en Roma, más que obra de legisladores, es expresión directa de la conciencia jurídica común. No sin razón, contraponía CICERON este proceso al de otras civilizaciones: "nostra res publica... aliquot constituta saeculis et aetatibus".

(81) L. CHIAZZESE, Diritto romano e civiltà moderna, BIDR, 51-52 (1948) p. 216.

(82) Phil. X, 20; cf. F. SCHULZ, art. "Libertas", Noviss. Dig. Ital., IX, p. 873.

(83) L. CHIAZZESE, Diritto romano..., art. cit., p. 218.

(84) Cf. J. DAZA, Aequitatis ratio, A.U.A. F. D., 1 (1982) p. 88 ss.

(85) U. ALVAREZ, Horizonte actual del Derecho Romano, Madrid, 1944, p. 428.

(86) A. GUARINO, Recensión a la obra de A. TORRENT, Salvius Iulianus, Salamanca, 1971, en IURA, 23 (1972), p. 195.

(87) G. NOCERA, Fonti del diritto e letteratura iuridica, IURA, 22 (1971), p. 83.

(88) Ibidem, p. 98; poco antes había llamado la atención sobre el hecho de que debe considerarse ya superado el tiempo del libro académico, "chenon ha neppure il pregio della dispensa universitaria di vecchia memoria ove almeno, pasando sopra al concetto di testo fisso e prefabbricato, si dava alla experienza culturale il significato di movimento, di cammino quotidianom (Ib., p. 97).

(89) Cf. A. LATORRE, La cuestión del método en la enseñanza del Derecho Romano, Romanitas, 1971, p. 222.

(90) Cf., por ejemplo A. D‘ORS, Derecho Privado Romano, Pamplona, 1978.

(91) Los autores suelen distinguir entre los conceptos de multidisciplinaridad (o grupo de materias sin más vínculo que el hecho de que figuran en un mismo plan de estudio); pluridisciplinaridad (conjunto de disciplinas que prestan afinidades entre si y se prestan a numerosas relaciones); interdisciplinaridad (cuando la influencia entre las diversas materias es mútua, pudiendo hablarse de un plano de igualdad entre varias de ellas); y transdisciplinaridad (esto es, la tendencia a una unificación de los saberes, superando la dispersión y la incomunicación de los mismos; en cierto sentido toda disciplina tiene a trascenderse a sí misma, buscando sus propios fundamentos y sus relaciones con las demás). Cf. D. ANTISSERI, L'Interdisciplinarità: premesse epistemologiche, Roma, 1973; idem, I fondamenti epistemologici del lavoro interdisciplinare, Roma, 1972; G. FREY, Methodological Problems of Indisciplinary Discussions, Ratio XV (1973) p. 270, ss.

(92) M. TUÑON DE LARA, ¿Qué es la Historia? Algunas cuestiones de historiología, Sistema, 9 (1975), pp. 5-26; F. FERNANDEZ SANTOS, Historia y Filosofia, Barcelona, 1969; VARIOS, Persona e comunità, Roma, 1974; J. GRÜNFELD, Historical Insight, Rvue de l'Universitté d'Ottawa, 38 (1968), pp. 73-96. 
(93) Cf. F. GUAGNER, La unidad de la ciencia: un problema básico de nuestro tiempo, Universitas, VI (1968), pp. 47-59.

(94) Un ejemplo de esta orientación puede verse en vol. Planificación cerebral del futuro del hombre, Madrid, 1973, en el cual representantes eminentes de la biología, la filosofía, la sociología, la sicología y la religión estudian interdisciplinarmente esta importante temática.

(95) Cf. R. MARIN IBAÑEZ, Interdisciplinaridad y enseñanza en equipo, Madrid, 1978.

(96) A. SANCHEZ DE LA TORRE, La pedagogía iusfilosófica, A. Fil. Der., VII, (1960) p. 236.

(97) Ibidem, p. 235.

(98) Ibidem, p. 226.

(99) J. GARCIA GARRIDO, Casuísmo y Jurisprudencia romana, M. 1972.

(100) E. VOLTERRA, Instituzioni di diritto privatto romano, Roma, 1967, p. 7-9; el autor establece una comparación del Derecho Romano con otros derechos conocidos de la antigüedad a fin de poner de manifiesto cómo en éstos falta "una qualsiasi sistematizazione dottrinale" ( $p$. 8), resalto el hecho sorprendente de que los griegos, creadores de los sistemas matemático y filosófico no hubieran construido un verdadero sistema jurídico (Ibidem, p. 9). Esta orientación logica del sistema romano es ya visible en las normas jurídicas más antiguas (piénsese, por ejemplo en los fragmentos arcáicos de las XII Tablas).

(101) Cf. BETTI, Esercitazioni romanistiche su casi pratici, Padua, 1930; PUGLIESE, // significato dell'insegnamento del diritto romano oggi, en Romanitas, 9 (1970), p. 437 y ss.

(102) U. ALVAREZ afirma que el seminario es el agrado último de la enseñanza universitaria, difícil de lograr, y aún más de sentirn (Horizonte..., ed. cit. p. 432). En él es posible una enseñanza adecuada de las fuentes y del método investigador, con todo su aparato de ciencias auxiliares y matrices. Exige, pues, no sólo la capacidad del que enseña, sino también un cierto grado de preparación en el que aprende. Su actividad debe encauzarse en dos sentidos: 1) análisis y valoración de las más recientes aportaciones científicas en el campo del Derecho Romano; 2) encauzar y dirigir nuevas investigaciones, sugiriendo los problemas y la posible forma de solucionarlos. Una muestra de la eficacia de los seminarios la encuentra U. ALVAREZ en obras como la Palingenesia de LENEL y otras similares que "bajo el nombre de los maestros llevan en sí el trabajo anónimo y eficaz de varias generaciones estudiantiles" (ibidem, p. 432).

(103) R. BADENES GASSET, Metodología, ed. cit., p. 422.

(104) G. MARTINOTTI - A. SCHIAVONE, Didattica: una indagine sui risultati di un seminario romanistico, en "Democracia e Diritto" 13-IV (1973) p. 277 ss.; una breve alusión a esta encuesta puede verse en LABEO, 20 (1974) pp. 305-306, a cargo de A. PUGLIESE.

(105) U. ALVAREZ, Horizonte actual del Derecho Romano, ed. cit., p. 428.

(106) P. RICOEUR, Réforme et révolution dans l'Universitė, Esprit, 36, 1968, p. 989; refiriéndose a la significación concreta que tuvo el Mayo francés de 1968 para muchos profesionales de la enseñanza decía M. JUFFE que «l'éducateur est celui qui rend possible la perpetuation du processus d'education. Cela implique qu'il ne peut ouvrir des moments de ce processus que s'il les parcourt lui-même. L'education est donc d'abord, et fondamentalement, auto-éducation" (relation d'autorité et relation d'education, Esprit 36 (1968) p. 331.

(107) Una de las causas de la actual "crisis educativa» tiene su raiz en la falsa premisa de que se parte todavia en muchos casos y según la cual todos los alumnos son iguales; de ahi la falta de atención al ritmo personal de aprendizaje de cada uno, la deserción de la llamada "ense- 
ñanza personalizada" (Cf. E. SCHATZ, The Teacher as a Learner, Washington, 1967); V. GARCIA HOZ, La enseñanza personalizada, Madrid, 1968; J. DELONCLE, Orientations actuelles de la psycho-pédagogie, Toulouse, 1972; H. HANNOUN, L'attitude non-directive de C. Rogers, Paris, 1972).

(108) J. MARITAIN, Education at the crossroads, Yale, 1950, p. 50.

(109) A. D'ORS, Volgarismo giuridico odierno, Boll. Infor. Ist. Giuridico Sp. in Roma, 1966, p. 3 y ss.

(110) G. GROSSO, Premesse generali.., ed. cit. p. 18.

(111) Cf. O. ROBLEDA, Introduzione..., ed. cit. pp. 33 y ss.

(112) J. ORTEGA Y GASSET, Del Imperio Romano, en «Las atlántidas y del Imperio romano", Rev. de Occidente, Madrid, 1976, p. 134; observa el autor que tal vez la causa de nuestra incapacidad para entender este hecho es el haber nacido uen un tiempo que ha triturado todo derecho con una maza extrajurídica denominada justicia" (/b. 134).

(113) B. BIONDI, Jus, en "Scritti luridici, I", Milano, p. 6.

(114) L. CHIAZZESE, Diritto romano e civiltà moderna. BIDR, 51-52 (1948) p. 213. No deja de ser significativo el hecho de que cuando los jurisconsultos romanos quieren determinar los principios supremos de la justicia, establecen reglas de conducta moral: honeste vivere, alterum no laedere, suum cuique tribuere...

(115) Cf. J. DAZA, Aequitatis ratio, art. cit., p. 79 ss.

(116) J. IGLESIAS, Espíritu del Derecho Romano, Madrid, 1980, p. 83.

(117) L. CHIAZZESE, Diritto romano..., art. cit., p. 213.

(118) J. IGLESIAS, Espiritu del Derecho Romano, op. cit., p. 84.

(119) B. BIONDI, Aspetti universali e perenni del pensiero giuridico romano, en Scritti Giuridici», I, p. 451; el autor recuerda que también en los tiempos modernos se ha hablado con frecuencia de una "humanización del Derechon, especialmente en el Derecho penal, ya que es evidente que se trata de un campo particularmente sensible a las exigencias de la humanitas.

(120) Cf. la nota bibliográfica selecta que inserta S. RICCOBONO (Jr.) en su trabajo HUMANITAS, en "Atti del Congr. Int. di Dir. Rom. e di St. del Dir.", II, 1948, p. 209-210.

(121) S. RICCOBONO (Jr.), Humanitas, en op. cit., p. 217.

(122) A diferencia de KRÜGER, que no concede ningún valor especial al hecho reconocido por èl, de que en las fuentes jurídicas se establezca una ecuación entre aequitas y humanitas, $F$. SCHULZ se apoya sobre él para justificar su visión histórica de la humanización del derecho, que tuvo lugar en el último periodo de la historia de Roma. S. RICCOBONO entiende que las dos posiciones son exageradas, derivándose ambas del espíritu interpolacionístico de O. GRADENWITZ (Humanitas, cit., p. 227). Le parece más propio decir que aquel periodo no debe atribuirse tanto la función humanizadora del derecho, con la progresiva eliminación de elementos paganos. La aequitas anterior deviene humanitas, la cual absorbe la mejor tradición jurídica renovada por el bonum et aequum y la desarrolla después con los preceptos y valores evangélicos.

(123) Inst. I, 6, 2.

(124) Apoyándose en motivos religiosos, JUSTINIANO mantuvo siempre la intención de consolidar la posición de la aequitas naturalis sobre bases verdaderamente permanentes, con el fin de hacer desaparecer los antiguos principios de un ius civile fundado sobre el nacionalismo y tomar en serio la igualdad de todos los hombres ante Dios (cf. F. PRINGSHEIM, Aequitas 
der christlichen Kaiser, en "Acta Congr. Iur. Int.», Roma, 1935, p. 148-149). Tampoco debe olvidarse que JUSTINIANO manifestó de diversas maneras su deseo de restaurar la unidad del antiguo imperio sobre el fundamento cristiano (cf. H. JAEGER, Justinien et l'episcopalis audientia; R.H.D.F., 38 (1960), p. 2597.

(125) Cf. J. C. MASCHI, Humanitas come motivo iuridico, Ann. Univ. Trieste, XVIII, 1948, p. 34 y ss.

(126) B. BIONDI, Humanitas nelle leggi degli Imperatori Romano-Cristiani, en "Scritti Giuridici", I, p. 593 y ss.

(127) Cf., entre otros, E. DELARUELLE, La doctrine de la personne humaine signe de contradiction entre Christianisme et Paganisme au III siècle, Bull. Litt. Eccles., 53 (1952), p. 161 ss.; C. SCHUTZ - R. SARACH, El hombre como persona, Madrid, 1963, passim.

(128) C. 3, 19, 2, 1 (a. 331); cf. MASCHI, Humanitas romana e caritas cristiana come motivi giuridici, lus, 1 (1950) p. 226 y ss.; la humanitas, para los emperadores cristianos es considerada bajo su aspecto religioso; los preceptos cristianos son calificados como praecepta humanitatis (C. 1,3,52).

(129) B. BIONDI, Humanitas nelle leggi..., art. cit., p. 610.

(130) Sirm. 13 (a. 419). J. IGLESIAS, estudiando la significación última del ius romanum, llega a la conclusión de que utodo lo que habla de bono et aequo tiene que ver, de alguna manera, con la humanitas, con la fides, con la pietas, con lo honestum, con la moderatio, con el decorum. Con algo que, compendiando a todo esto se llama officium" (Espiritu del Derecho Romano, op. cit., p. 85).

(131) P. DE FRANCISCI, Idee vecchie e nuove intorno alla formazione del diritto romano, en "Scritti Ferrini», I, Milano, p. 199 y ss.

(132) E. BETTI, Forma e sostanza della interpretatio prudentium; en "Atti Verona", II, Milano, 1951, p. 103 y ss. Cf. también B. BIONDI, Interpretatio prudentium e legislazione, en "Scritti Giuridici», I, Milano 1965, pp. 323-364; según este autor, los prudentes proceden de determinados conceptos fundamentales, en cuanto que las nociones de patria potestas, de dominium, de obligatio, de successio, de actio, son las figuras fundamentales y como las células del sistema jurídico. Ningún legislador las ha reconocido, sino más bien la fuerza de la tradición que era valorada por su correspondencia a la realidad de la vida (pp. 140-141).

(133) G. GROSSO, Premesse generali al corso di diritto romano, Torino, 1960, p. 66.

(134) POMPONIO, en D. 1, 2, 2, 12; así es como, siguiendo las mismas afirmaciones de los romanos contraponemos nosotros su jurisprudencia a la nuestra, en cuanto esencialmente creadora de derecho; y es también así como habitualmente se pone la interpretatio prudentium entre las fuentes de Derecho. GROSSO (Premesse..., p. 68 ss.) observa, sin embargo que toda interpretario, incluida la de la jurisprudencia romana, tiene formalmente uun valore ricognitivo del diritto, non creativo nel senso di un organo che pone ex novo la norma giuridica».

(135) ROTONDI ha hecho notar que de casi ochocientas rogationes legislativas, desde principios de la República hasta el siglo primero, sólo treinta hacen referencia al derecho privado (Scritti Giuridici, I, Milán 1922, p. 7. Cf. además, Ricerche sulla produzione legislativa dei comizi romani, p. 43-66).

(136) L. MITTEIS, Röm. Privatr. bis auf die Zeit Diocletians, I, 1908, p. 30-37.

(137) J. PAOLI, Legitimum ius, D.A.S.J. (Mélanges H. Lévy-Bruhl), p. 215 ss.

(138) A. GUARINO, L'ordinamento giuridico romano. Lezioni instituzionali di diritto romano, Nápoles, 1956, especialmente p. 101 ss. KASER, por el contrario, sostiene quee el ius es un campo ajeno a los mores maiorum (Mores mariorum und Gewohnheitsrecht, S.Z., 59 (1939), p. 52 ss.). VOLTERRA ha probado, a nuestro juicio, la improcedencia de esta distinción que, por otra parte, no ha sido aceptada en general (Sui mores della Famiglia romana, Rendiconti Accademie Nazionale dei Lincei, 1949). 
(139) Cf. G. ROTONDI, op. cit., p. 7 ss. Creemos que la opinión de este autor sigue manteniendo su validez pese a las objeciones hechas por CONSENTINI (// carattere della legis/azione comiziale romana di diritto privato, en A. G., 1944, p. 130 ss.)

(140) B. BIONDI, Interpretatio prudentium e legislazione, art. cit., p. 323, ss.

(141) P. FUENTESECA, La necesidad de retornar al estudio del Edicto del Pretor, en "Investigaciones de derecho procesal romanon, Salamanca, 1969, p. 67-92.

(142) E. BETTI, Forma e sostanza della "interpretatio prudentium"; en Atti Congreso I. Dir. Rom. (Verona), II, Milán, 1951, p. 103-120.

(143) P. FUENTESECA, op. cit., p. 90; por otra parte, el autor subraya que el estudio del edictum es de una importancia excepcional para desentrañar la evolución histórica del Derecho Romano desde fines de la República al pensamiento clásico (ibidem).

(144) S. CRUZ, Direito Romano, I, Coimbra, 1973, p. 56.

(145) P. FUENTESECA, Lecciones de Historia del Derecho Romano, Salamanca, 1970, pp. 57-58. El autor añade que ula valoración de la vida político-constitucional de Roma se ha hecho en gran parte partiendo de conceptos de la ciencia política moderna o del Derecho Público de nuestros tiempos. No se han tenido en cuenta nociones romanas como la auctoritas... tampoco se han tenido en cuenta la noción de imperium. De ahi que hoy no podamos explicarnos bien la combinación de los tres pilares de la Constitución romana, magistratura, senatus, populus (ibidem, p. 58).

(146) Ibidem, p. 58.

(147) B. BIONDI, Diritto e politica nel pensiero romano, en «Scritti giuridici», I, ed. cit. pp. 47-48.

(148) F. SCHULZ, I principi del diritto romano, Firenze, 1946, p. 206; en el texto resumimos a continuación la posición de SCHULZ sobre la certeza del Derecho en Roma. El autor concluye este cap. de su obra diciendo que "no es la seguridad del comercio jurídico lo que está en el corazón de los romanos, sino "la sicureza del diritto quesito"", p. 218.

(149) C. A. MASCHI, Certezza del diritto nel diritto romano e nel pensiero contemporaneo, RIDA, 6 (1959) pp. 338-345.

(150) F. CARNELUTTI, La crisi del diritto, Padua, 1963, p. 167.

(151) U. ALVAREZ, La Jurisprudencia romana en la hora presente, Madrid, 1966, p. 14-16.

(152) B. BIONDI, La legislazione di Augusto, en "Scritti Giuridici", II, p. 83.

(153) C. A. MASCHI, Certezza del diritto e potere discrezionale del magistrato nel diritto romano, en «Studi Betti», III, p. 411-449.

(154) Ibidem. p. 419; el autor considera que son notas esenciales del Derecho Romano clásico el principio de la pluralidad de las fuentes del derecho (lo cual contribuye a una más completa y diferenciada actividad normativa y jurisprudencial), el principio de no centralización estatal de la actividad normativa, la conciliación entre diversas actividades (normativa y jurisprudencial en el pretor; doctrinal y normativa en la jurisprudencia) y la conciliación entre lo viejo y lo nuevo a través de la tradición, asi como la adherencia del derecho a la realidad (p. 420); cf. también este mismo autor en su lib. sobre "La concezione naturalistica del diritto en degli instituti giuridici romanin, Milano 1937.

(155) D. 1, 3, 21.

(156) El texto de JULIANO a que nos referimos en éste: non omnium quae a maioribus constituta sunt, ratio reddi potest» D. 1, 3, 20. 
(157) A. TORRENT, Conceptos..., op. cit., p. 131; SCHULZ señala que las reflexiones críticas sobre el derecho constitucional romano pueden haber sido practicadas también en los ambientes romanos, a imitación de los griegos; pero en Roma estas tendencias han tenido expresión literaria solamente en el libro de un griego (POLIBIO) y de un romano demasiado ligado a sus modelos griegos (CICERON).

(158) Esta expresión se encuentra repetidas veces en los dos arts. de MASCHI citados anteriormente (cf. v. c., Certezza del diritto nel diritto romano, art. cit., pp. 340 y 343).

(159) GAYO, 1, 6.

(160) CICERON, De inventione, 2, 22, 67. Cf. J. DAZA, Kyrios Nomos, Madrid, 1976.

(161) C. A. MASCHI, Certezza del diritto..., art. cit. p. 343.

(162) ID., Certezza del diritto e potere..., art. cit. p. 447. 